\title{
WIND TUNNEL INVESTIGATION OF DYNAMIC TRIMMING ON UPWIND SAIL AERODYNAMICS
}

\author{
Nicolas Aubin \\ Naval academy research Institut - IRENAV, France \\ Benoit Augier \\ Naval academy research Institut - IRENAV, France \\ Matthieu Sacher \\ Naval academy research Institut - IRENAV, France \\ Patrick Bot \\ Naval academy research Institut - IRENAV, France \\ Frédéric Hauville \\ Naval academy research Institut - IRENAV, France
}

Richard G. J. Flay

Yacht Research Unit, Department of Mechanical Engineering, The University of Auckland, New Zealand

Manuscript received September 16, 2008; revision received May 8, 2009; accepted August 26, 2009.

\begin{abstract}
An experiment was performed in the Yacht Research Unit's Twisted Flow Wind Tunnel (University of Auckland) to test the effect of dynamic trimming on three IMOCA 60 inspired mainsail models in an upwind $\left(\beta_{A W}=60^{\circ}\right)$ unheeled configuration. This study presents dynamic fluid structure interaction results in well controlled conditions (wind, sheet length) with a dynamic trimming system. Trimming oscillations are done around an optimum value of $C F_{o b j}$ previously found with a static trim. Different oscillation amplitudes and frequencies of trimming are investigated. Measurements are done with a 6 component force balance and a load sensor giving access to the unsteady mainsail sheet load. The driving $C F_{x}$ and optimization target $C F_{o b j}$ coefficient first decrease at low reduced frequency $f_{r}$ for quasi-steady state then increase, becoming higher than the static state situation. The driving force $C F_{x}$ and the optimization target coefficient $C F_{o b j}$ show an optimum for the three different design sail shapes located at $f_{r}=0.255$. This optimum is linked to the power transmitted to the rig and sail system by the trimming device. The effect of the camber of the design shape is also investigated. The flat mainsail design benefits more than the other mainsail designs from the dynamic trimming compared to their respective static situtation. This study presents dynamic results that cannot be accurately predicted with a quasi-static approach. These results are therefore valuable for future FSI numerical tools validations in unsteady conditions.
\end{abstract}

Keywords: wind tunnel, upwind, unsteady, fluid-structure interaction 


\section{NOMENCLATURE}

A Dynamic trimming amplitude [mm]

c Reference chord [m]

$C F_{i} \quad$ Force coefficient in the $i$-axis direction [-]

$C F_{o b j} \quad$ Optimization target coefficient [-]

$C F_{\text {sheet }} \quad$ Force coefficient in the mainsail sheet [-]

$f \quad$ Input frequency $[\mathrm{Hz}]$

$f_{r} \quad$ Reduced frequency [-]

$F_{i} \quad$ Force in $i$-axis direction [N]

$F_{\text {sheet }} \quad$ Force in the mainsail sheet [N]

$h \quad$ Mainsail luff length [m]

$L_{c a r} \quad$ Car traveller line length [mm]

$L_{\text {sheet }} \quad$ Mainsail sheet length [mm]

$P \quad$ Mechanical power from the sheet [mW]

$q \quad$ Dynamic pressure $[\mathrm{Pa}]$

$S \quad$ Sail mould area $\left[\mathrm{m}^{2}\right]$

$T \quad$ Time period of oscillation [s]

$U_{\text {ref }} \quad$ Reference wind velocity $\left[\mathrm{m} \cdot \mathrm{s}^{-1}\right]$

$\overrightarrow{V_{A W}} \quad$ Apparent wind velocity vector $\left[\mathrm{m} \cdot \mathrm{s}^{-1}\right]$

$\mathrm{x} \quad$ Optimization variables

$\beta_{A W} \quad$ Apparent wind angle value [ $\left.{ }^{\circ}\right]$

$\Delta L_{\text {sheet }}$ Instantaneous sheet length centred on the static optimum length [mm]

$\rho \quad$ Density of air $\left[\mathrm{kg} \cdot \mathrm{m}^{-3}\right]$

$\Omega \quad$ Domain of variation of the optimization variables

AWS Apparent wind speed $\left[\mathrm{m} \cdot \mathrm{s}^{-1}\right]$

AWA Apparent wind angle $\left[^{\circ}\right]$

CFD Computational Fluid Dynamics

EGO Efficient Global Optimization

FSI Fluid-Structure Interaction

GP Gaussian Process

MSflat Mainsail with zero camber for the design shape

MSmax Mainsail with maximum camber for the design shape

MSstd Mainsail with standard camber for the design shape

RANS Reynolds-averaged Navier-Stokes

YRU Yacht Research Unit

\section{INTRODUCTION}

A challenging task in yacht design modeling and simulation is the analysis of dynamic effects in the Fluid Structure Interaction (FSI) of the yacht sails and rig. The dynamic behavior can be caused by the sea state or the wind, but can also be caused by the action of the crew while trimming. Literature has pointed out the difficulty of considering the realistic sailing environment of a yacht (Charvet et al., 1996; Marchaj, 1996; Garrett, 1996). Recent studies have underlined the importance of considering the dynamic behavior: forced pitching motion in the wind tunnel (Fossati and Muggiasca, 2012), 2D simplified pitching (Gerhardt et al., 2011), interaction of yacht sails in unsteady conditions (Gerhardt, 2010), full-scale experi- 
ments and simulations (Augier et al., 2012; Augier et al., 2013; Augier et al., 2014), and downwind sails (Collie and Gerritsen, 2006; Deparday et al., 2014). Downwind sail design is where the gain from a dynamic aero-elastic analysis seems to be potentially the greatest due to the large motion and the induced large load variation. The main findings of these different studies are the same, i.e. the aerodynamics can be predicted more accurately with an unsteady approach.

To account for this dynamic behavior, several Dynamic Velocity Prediction Programs (DVPPs) have been developed (Masuyama et al., 1993; Masuyama and Fukasawa, 1997; Richardt et al., 2005; Keuning et al., 2005) which need models of dynamic aerodynamic and hydrodynamic forces. While the dynamic effects on hydrodynamic forces have been studied extensively, the unsteady aerodynamic behavior of sails has received much less attention. Schoop and Bessert (2001) first developed an unsteady aeroelastic model in potential flow dedicated to flexible membranes but neglected the inertia. In a quasi-static approach, a first step is to add the velocity induced by the yacht's motion to the steady apparent wind to build an instantaneous apparent wind (Richardt et al., 2005; Keuning et al., 2005) and to consider the aerodynamic forces corresponding to this instantaneous apparent wind using force models obtained in the steady state.

Recently, advanced computational resources have enhanced numerical simulations and have allowed coupling of fluid and structural solvers dedicated to yacht sails (Renzsh and Graf, 2010; Chapin and Heppel, 2010; Trimarchi et al., 2013; Ranzenbach et al., 2013). In past years, IRENav and the K-Epsilon company have developed numerical tools dedicated to the simulation of the dynamic behavior of yacht sails. The FSI potential model ARAVANTI has been validated by full-scale measurements (Augier et al., 2012) and enables numerical studies of a yacht pitching in a head swell (Augier et al., 2013; Augier et al., 2014), showing a clear break with the quasi-static approach. The recent RANS FSI coupling ARA-FINE ${ }^{\text {TM }}$ /Marine (Durand et al., 2014) is required to simulate cases with strong separation for downwind simulations, but it is very time and CPU consuming.

Even though some advanced models are now available for sail aerodynamics, there is a real need for detailed validation of numerical simulations in order to provide reliable design tools for the sailing industry. Controlled experiments are also a great opportunity to understand the physics of FSI of yacht sails. Unfortunately, realistic and reliable experimental data is scarce and the validation of models in real conditions is difficult (Augier et al., 2012; Fossati et al., 2015). In this context, wind tunnel testing and full-scale testing are required for comparison and validation (Flay, 1996; Renzsch and Graf, 2013; Le Pelley et al., 2002). Wind tunnel testing has the advantage of being in a controlled environment where a balance can be used to measure the forces created by the sails on the boat frame (Viola and Flay, 2010; Fossati, 2010; Fossati and Muggiasca, 2009; Fossati and Muggiasca, 2010; Wright et al., 2010). Pressure and flying shape measurements can also be performed in wind tunnels (Lasher and Richards, 2007; Graf and Müller, 2009; Viola and Flay, 2011; Viola et al., 2013). In a recent study, Gerhardt et al. (2011) developed an analytical model to predict the unsteady aerodynamics of interacting yacht sails in 2D potential flow, and performed 2D wind tunnel oscillation tests with a motion range typical of a 82-foot $(25 \mathrm{~m})$ racing yacht (1992 International America's Cup Class). Recently Fossati and Muggiasca (2009), Fossati and Muggiasca (2010), Fossati and Muggiasca (2011), and Fossati and Muggiasca (2012) studied the aerodynamics of model-scale rigid sails in a wind tunnel, and showed that pitching motion has a strong and non-trivial effect on aerodynamic forces.

A dedicated experiment has been developed in the Yacht Research Unit Twisted Flow Wind 
Tunnel, University of Auckland, to study the aerodynamics of dynamic trimming. The model was simplified to a simple model-sized IMOCA 60 mainsail and a mast with no shrouds. We measured the effect of dynamic trimming on the forces $\left(F_{x}, F_{y}\right)$ with the balance and the load in the sheet $\left(F_{\text {sheet }}\right)$ for a given incoming wind $\left(U_{\text {ref }}=3.5 \mathrm{~m} / \mathrm{s}\right.$ at $1.5 \mathrm{~m}$ height at model-scale location in an empty wind tunnel configuration) for 3 different sail design shapes.

In the first part of the paper, we describe the experimental set up and we define the optimum trimming. In the second part, the results are presented for different trimming oscillation amplitudes and frequencies and for different sail design shapes. Finally the influence of these different parameters on the global performance of the rig is discussed.

\section{EXPERIMENTAL SETUP}

Experiments were performed thanks to the Sailing Fluids collaboration program in the Twisted Flow Wind Tunnel of the Yacht Research Unit of the University of Auckland described in (Flay, 1996).

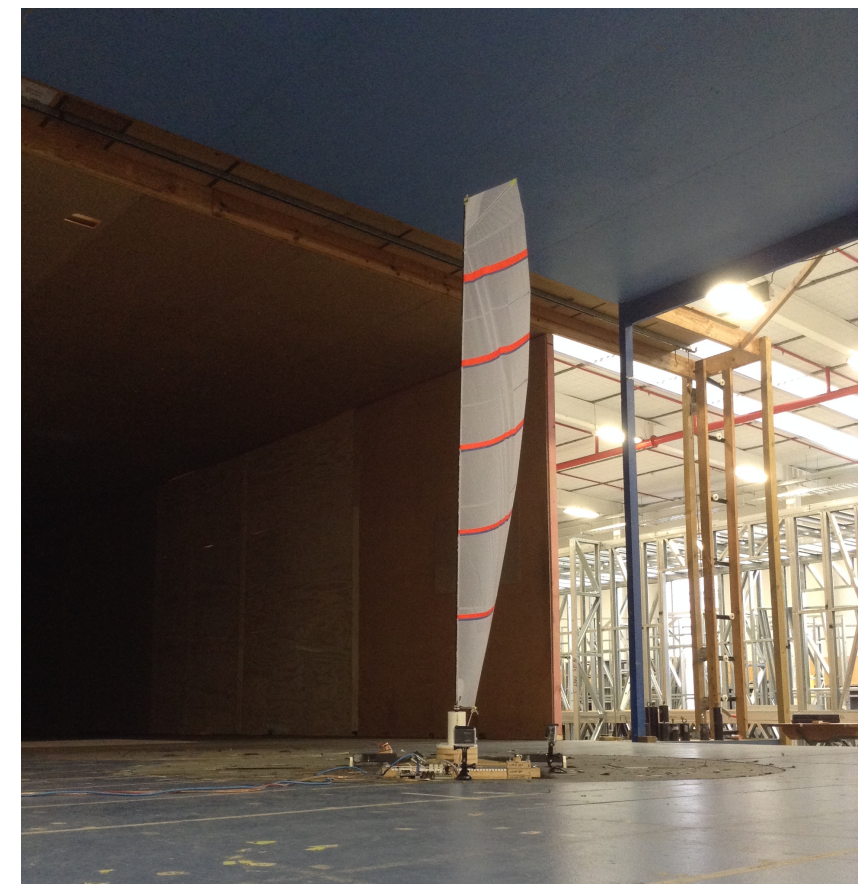

Figure 1. Model mainsail in YRU Twisted Flow Wind Tunnel, University of Auckland

An 1/13th scale IMOCA 60 foot design mainsail was designed and built by Incidences Sails, using SailPack software developed by BSG Developements, for these experiments. The static and dynamic trimming configurations are presented next in their respective part. Figure (1) shows the $2.2 \mathrm{~m}$ long mast with the scaled mainsail in the $7.2 \mathrm{~m}$ wide by $3.5 \mathrm{~m}$ tall open jet test section of the YRU wind tunnel. Sail geometry is defined in figure (8a). The rig is composed of a cantilevered $14 \mathrm{~mm}$ circular section carbon mast without spreaders, backstay or forestay. The objective is to create a simple bench experiment to study the aerodynamic effect of the dynamic trimming and to validate trimming optimization methods. The experiment includes Fluid Structure Interaction with mast deformation for use in numerical model comparisons. A six-component force balance located under the floor of the wind tunnel measures aerodynamic forces. The $x$-direction is aligned with the model longitudinal direction forward (drive force), the $y$-direction is perpendicular positive port-side and measures the side force and the $z$-direction is vertical as shown in figure (8a). The balance precision was 
verified by calibration testing and the uncertainty on $x, y$ and $z$ axis are $\pm 0.09 \mathrm{~N}, \pm 0.11 \mathrm{~N}$ and $\pm 0.27 \mathrm{~N}$ respectively. A load sensor of $50 \mathrm{~N}$ range measures the sheet load with a precision of $\pm 0.02 \mathrm{~N}$. The flying shape is measured with five orange stripes (see figure (1)) through the VSPARS acquisition system (Le Pelley and Modral, 2008). The sampling frequency of the system measurement is $200 \mathrm{~Hz}$ and every run is recorded over $30 \mathrm{~s}$.

The velocity profile follows the empty wind tunnel boundary layer profile and is not twisted (no vanes in the flow). The apparent wind speed (AWS) is $U_{\text {ref }}=3.5 \mathrm{~m} / \mathrm{s} \pm 0.15 \mathrm{~m} / \mathrm{s}$ - measured at $1.5 \mathrm{~m}$ high at the model-scale location in an empty configuration- and an apparent wind angle (AWA) set to $60^{\circ} \pm 2^{\circ}$. A Pitot tube in the wind tunnel roof, was used to measure the dynamic pressure during each run. The mean value $\overline{q(t)}$ calculated for each test was used for the normalization of equations in order to correct for the possible fluctuations in the wind tunnel flow speed. The recording system architecture is given in figure (2) and provides the force and dynamic pressure signals used to compute the averaged aerodynamic forces and sheet loads defined by the following equations:

$$
C F_{i}(t)=\frac{F_{i}(t)}{\overline{q(t)} S}
$$

This equation defines the force coefficient where $i$ stands for $x$ for the drive force coefficient, $y$ for the side force coefficient and sheet for mainsail sheet load coefficient. $q(t)=\frac{1}{2} \rho U(t)^{2}$ is the dynamic pressure measured during the run by the Pitot tube. Using the same convention on $i$, the mean values presented in our study are defined as:

$$
C F_{i}=\overline{C F_{i}(t)}=\frac{\overline{F_{i}(t)}}{\overline{q(t) S}}
$$

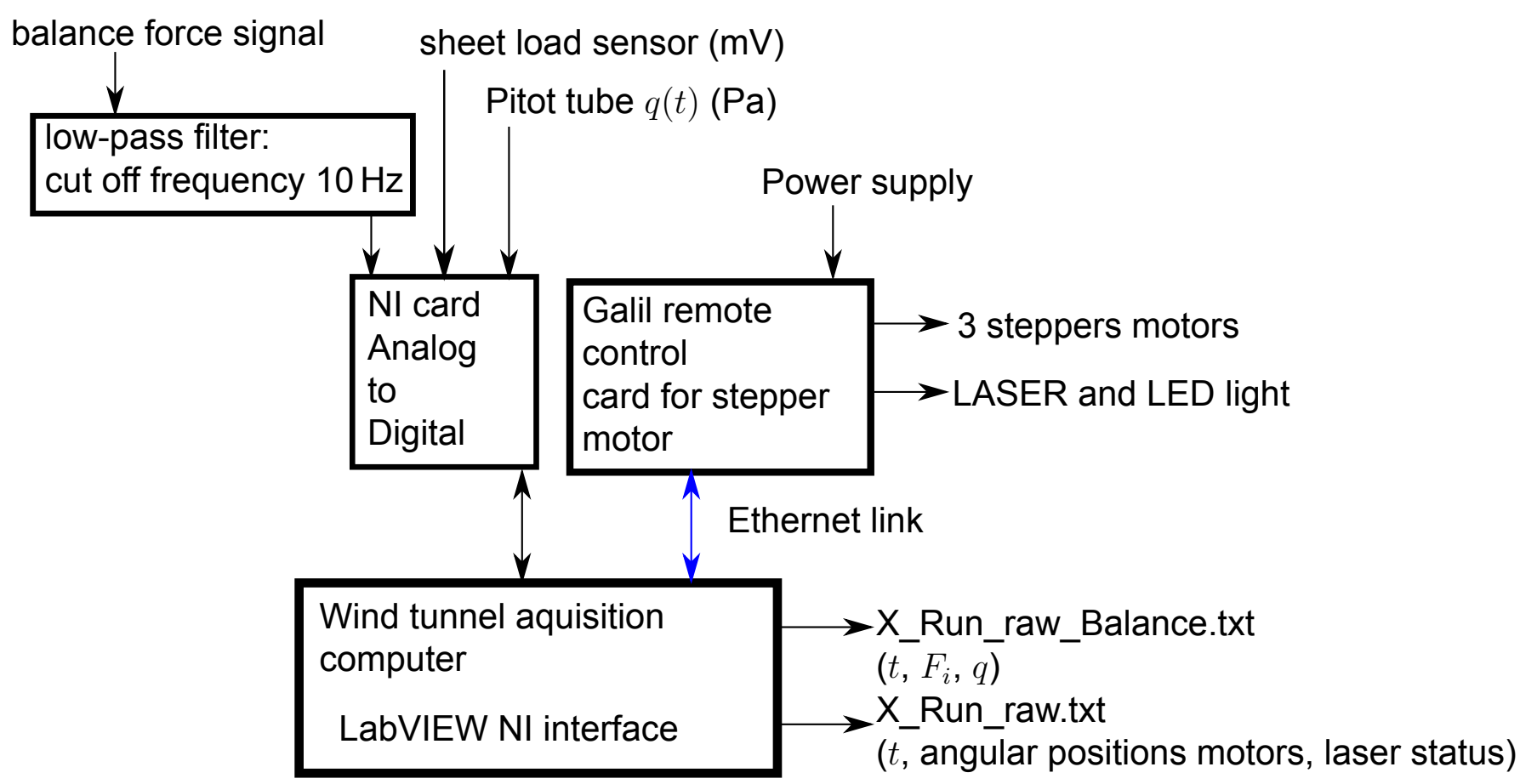

Figure 2. Architecture of the experimental apparatus. (NI stands for National Instruments ${ }^{\mathrm{TM}}$ ) 
Several static calibration operations were carried out to ensure the accuracy of the static forces measured. Controlled dynamic experiments were also achieved to ensure the efficiency of the system to record dynamic data for the tested conditions. Dynamic results presented in this article are achieved with dynamic frequencies below the first natural frequency of the mast.

\section{OPTIMUM TRIMMING}

\section{Static trim set up}

Different sail design shapes were tested. Three sails, made from the same sail cloth were designed with different cambers:

- MSstd = camber of the full-scale sail $(9.2 \%$ at the reference stripe $)$

- MSflat = no camber

- $M S m a x=$ more camber than MSstd $(11.7 \%$ at the reference stripe)

A first test was performed in order to determine the best trim for the studied $\beta_{A W}=60^{\circ}$ in the parameter space $\left(L_{\text {sheet }}, L_{c a r}\right)$ which geometric configuration is described in figure (3). The static trimming system shown in figure (4) is composed of three stepper motors and a control card and was used in order to modify the main sheet length $L_{\text {sheet }}$ and main car position $L_{c a r}$. Therefore, the mainsail trimming was imposed remotely without any human contact in the wind tunnel. The uncertainty of imposed trimming was estimated to be $\pm 2 \mathrm{~mm}$ through repeated measurements. The model was placed on the balance and the sail was statically trimmed using three stepper motors as winches: two motors used to trim the traveller position $L_{c a r}$ and one centered motor used to trim the main sheet length $L_{\text {sheet }}$. An optimization process is used to determine the best trimming.

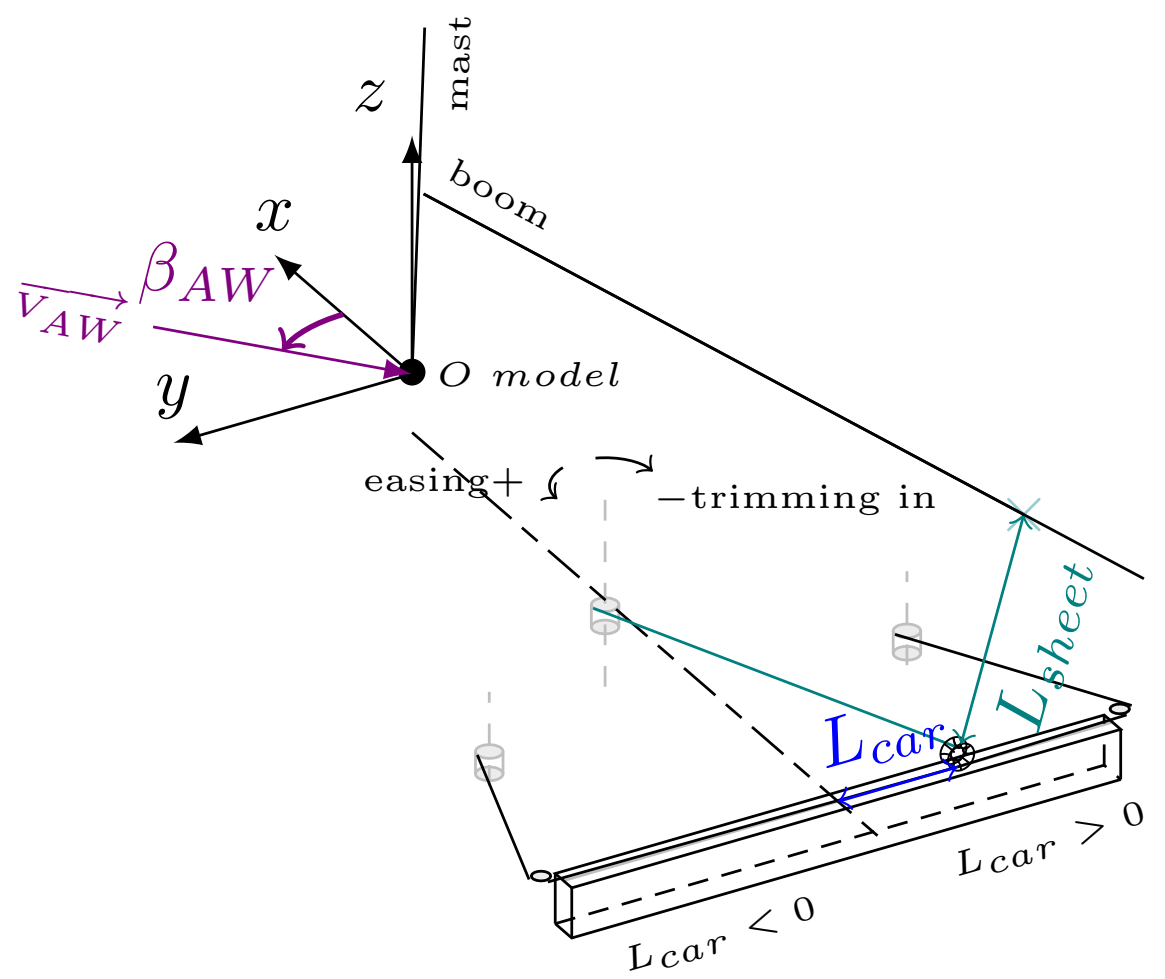

Figure 3. Experimental set up for static trimming: $\left(\mathrm{L}_{\text {car }}, \mathrm{L}_{\text {sheet }}\right)$ represent the parameter space. 


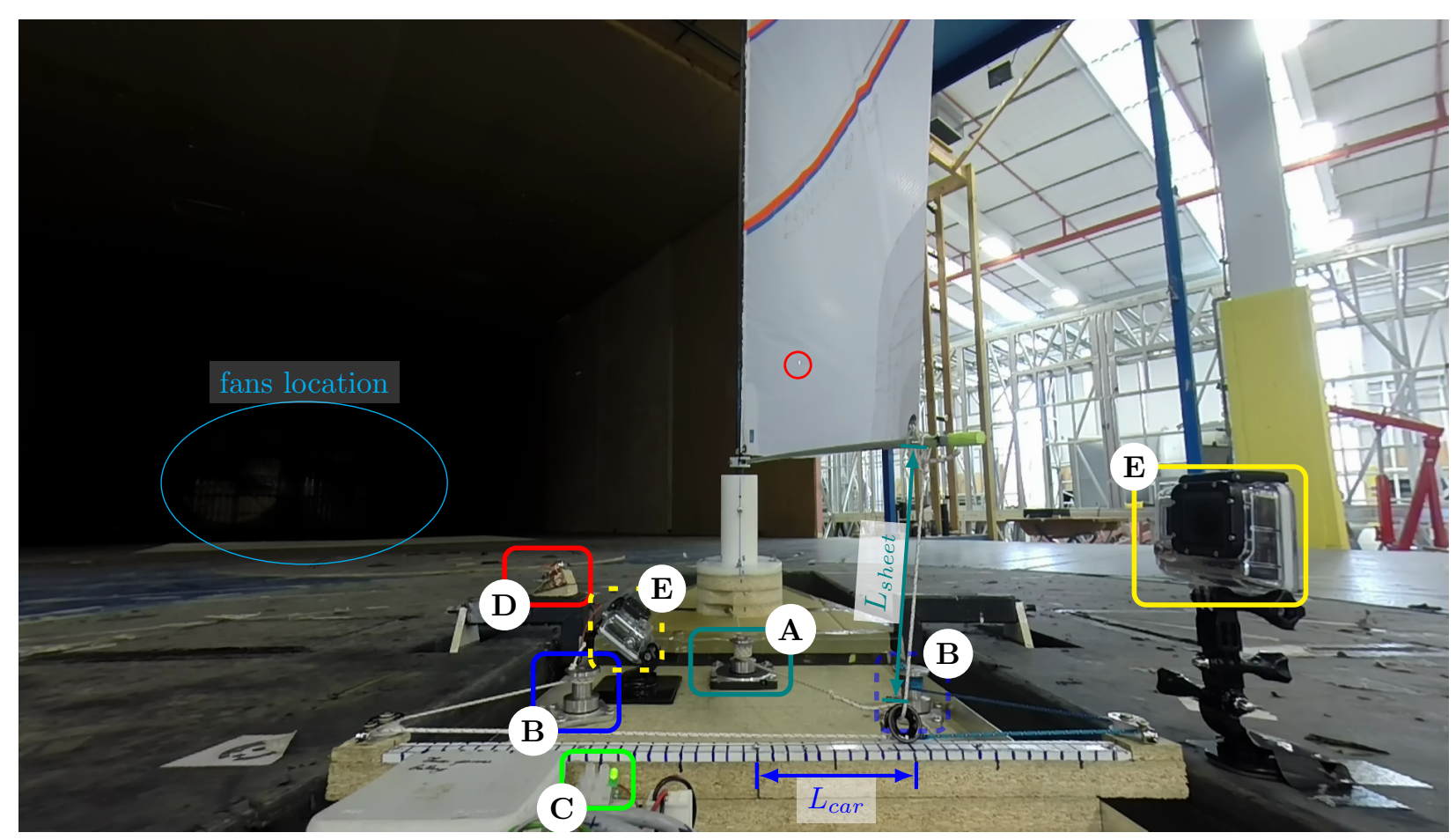

Figure 4. Photograph of the experimental set up for static trimming. A: mainsail sheet winch, B: car traveller winches, C: synchronisation LED, D: synchronisation laser (red circle represents the location of the laser impact onto the sail), E: camera. The load sensor if not mounted in this photograph. Fish eye effect has been corrected.

\section{Optimization process}

The optimization problem can be formally expressed as

$$
\mathbf{x}_{\mathrm{opt}}=\underset{\mathbf{x} \in \Omega}{\arg \min }-C F_{o b j}(\mathbf{x})
$$

where $\mathrm{x}$ are the optimization variables, $\Omega$ the domain of variation of the optimization variables, and $C F_{o b j}: \Omega \mapsto \mathbb{R}$ is the measurement of performance to be maximized.

In this work, we use an Efficient Global Optimization (EGO) (Jones et al., 1998; Duvigneau and Chandrashekar, 2012) method that relies on Gaussian Process (GP) to approximate the mapping $C F_{o b j}: \Omega \mapsto \mathbb{R}$. This statistical approach uses a coarse set of performance evaluations at some selected parameters values $\mathbf{x} \in \Omega$ to infer a GP $\mathcal{G}(\mathbf{x}) \approx C F_{\text {obj }}(\mathbf{x})$. This surrogate-based optimization procedure is embedded in an iterative scheme, where new evaluations of the performance at carefully selected new points $\mathbf{x}$ are introduced in order to refine the GP approximation in regions of $\Omega$ of interest, that is susceptible to include the optimum. The GP approach is expected to improve the direct optimization of $C F_{o b j}$ by a) requiring an overall lower number of performance evaluations, compared to direct gradient-free approaches, and b) enabling the use of efficient global optimization tools. Another interest of GP-based optimization is that it naturally accommodates for errors and noise in the performance evaluation. This feature is especially attractive in the case of optimizations relying on complex numerical FSI simulations, where both modeling and numerical errors are expected to be significant and hardly reducible (Sacher et al., 2017).

The present objective is to find the optimal trimming of the sail, for a performance criterion 
combining the drive and side aerodynamic force coefficients:

$$
C F_{o b j}(\mathbf{x})=C F_{x}(\mathbf{x})+0.1 C F_{y}(\mathbf{x}) .
$$

In addition to the thrust coefficient to be maximized, the objective function in (4) penalizes the (negative) side force coefficient $C F_{y}$, with a weight coefficient 0.1 , to account for the hydrodynamic drag and leeway that are detrimental to yacht performance (Sacher et al., 2015). Illustrative results at the convergence of the EGO procedure applied to the MSstd sail are given in figure (5), where figure (5a) shows the colour contours of the posterior mean as a function of the trimming parameters $L_{\text {car }}$ and $L_{\text {sheet }}$ over the optimization domain, and figure (5b) shows the corresponding standard deviation. The posterior mean of $C F_{o b j}$ contains a single well-defined global optimum in $\Omega$. It is seen many exploration points (black circles) in the neighbourhood of the optimum (crossed black circle) and some of them have been added far away for reducing the model uncertainty in non-explored areas during the first initial sampling step (black squares). The standard deviation of the GP model in figure (5b) is minimal close to the optimum, but remains finite because of the noisy experimental measurements.

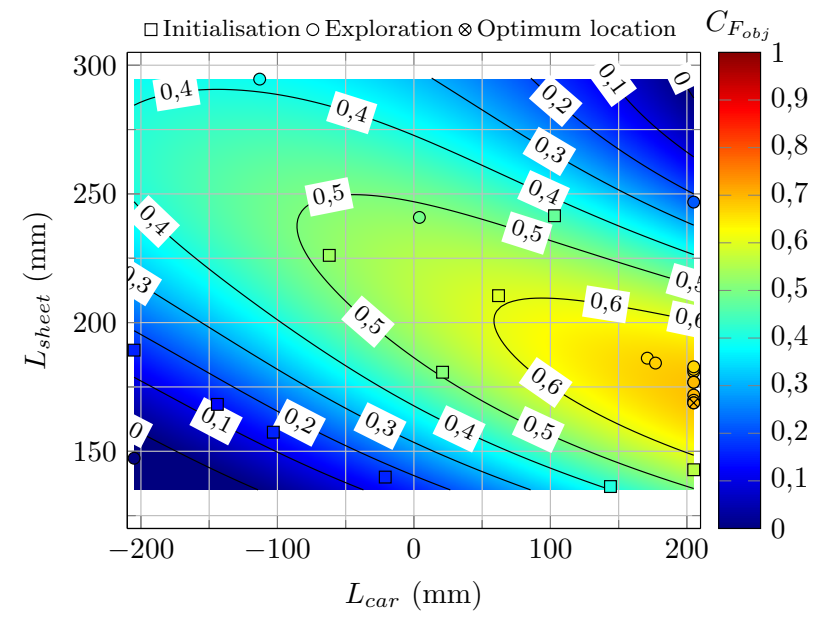

(a) GP model mean.

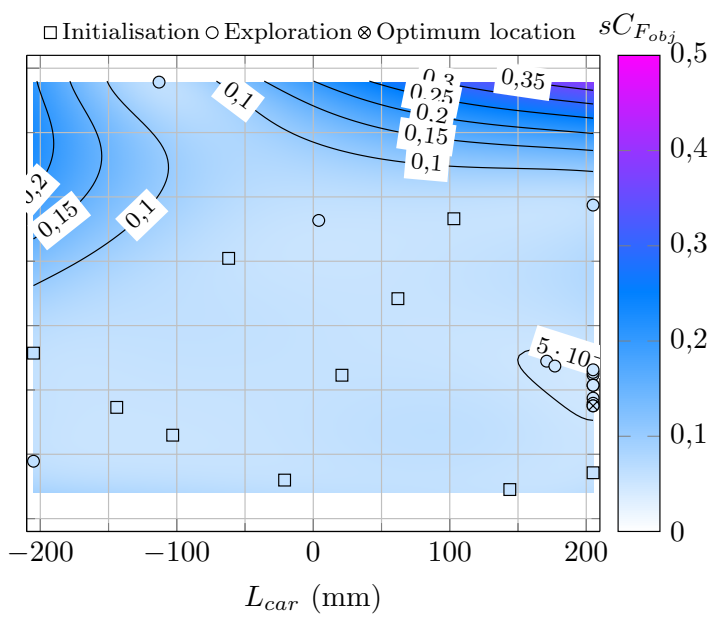

(b) GP model standard deviation.

Figure 5. GP model of $C F_{o b j}(\mathbf{x})$, MSstd sail at $\beta_{A W}=60^{\circ}$

Figure (6) summarizes the three performance responses in $\Omega$ of the MSmax, MSstd and MSflat sails. Three iso-lines of $C F_{o b j}$ are plotted for each sail. It is clear that MSflat is the worst sail as it does not reach the $C F_{o b j}=0.65$ level, and trimming areas where $C F_{o b j}=0.55$ and $C F_{\text {obj }}=0.50$ are smaller than for MSmax and MSstd. The maximum and standard camber sails are relatively close in term of performance responses. 


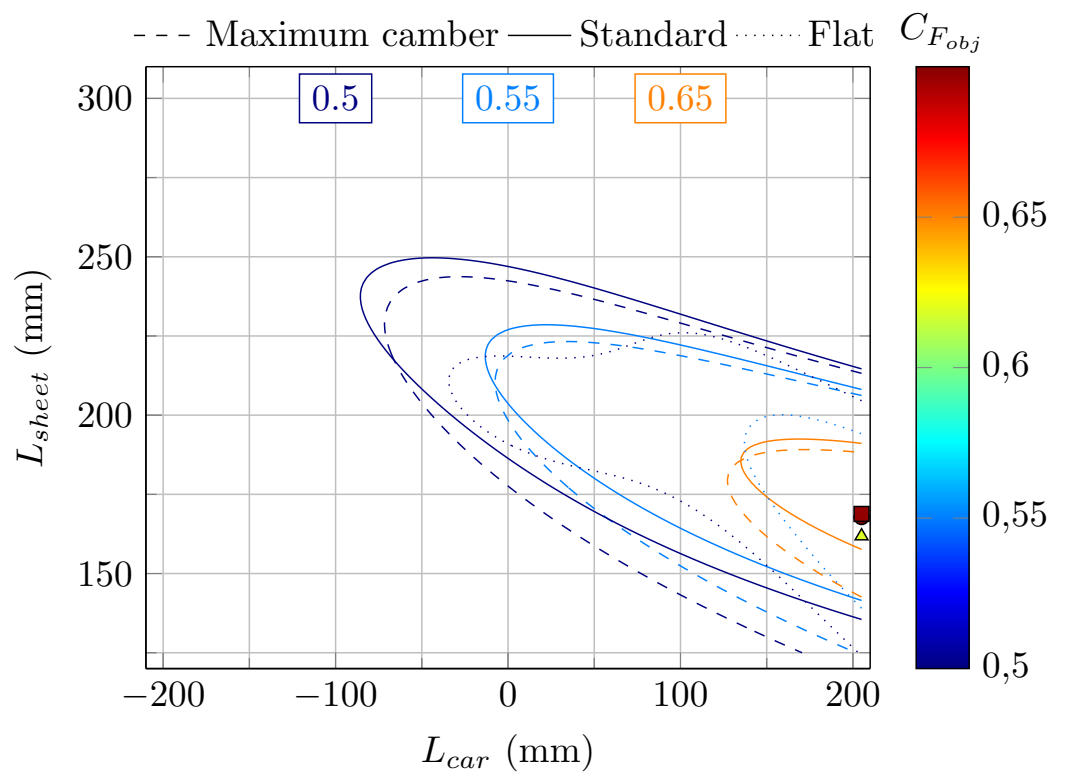

Figure 6. $C F_{o b j}(\mathbf{x})$ performances of MSmax, MSstd and MSflat for $\beta_{A W}=60^{\circ}$. The disk mark is associated to the maximum camber mainsail experimental optimum, the square mark is associated to the standard mainsail experimental optimum, the triangle mark is associated to the flat mainsail experimental optimum

Figure (7) shows the evolution of the performance results tested for two lower apparent wind angles. The lower the apparent angle, the more centered the optimum location $\left(L_{c a r}\right.$ close to the boat centreline for $\beta_{A W}=25^{\circ}$ ) and the more trimmed the mainsail sheet. The design corresponding to the standard mainsail presents more performance in close hauled conditions. More details of the GP-based optimization procedure with applications to experimental and numerical FSI sail trimming optimization are available in Sacher et al. (2017).

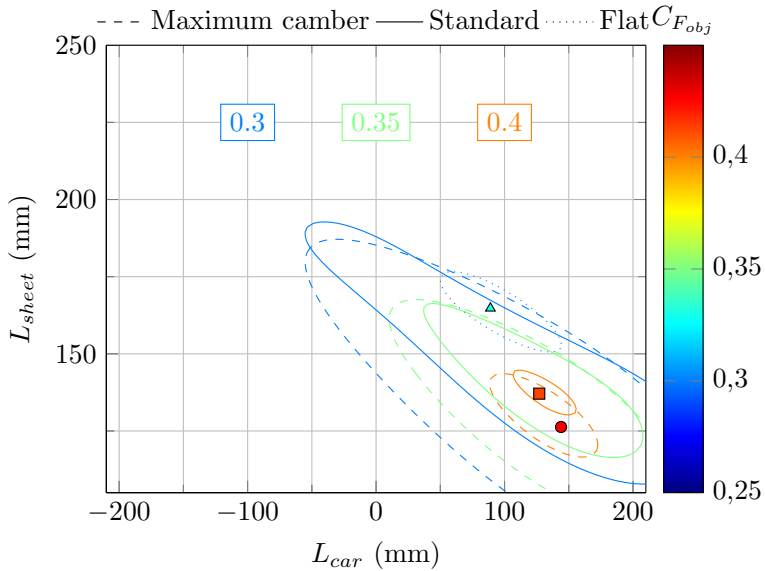

(a) $C F_{o b j}(\mathbf{x})$ performances of MSmax, MSstd (b) $C F_{o b j}(\mathbf{x})$ performances of MSmax, MSstd and MSflat for $\beta_{A W}=40^{\circ}$

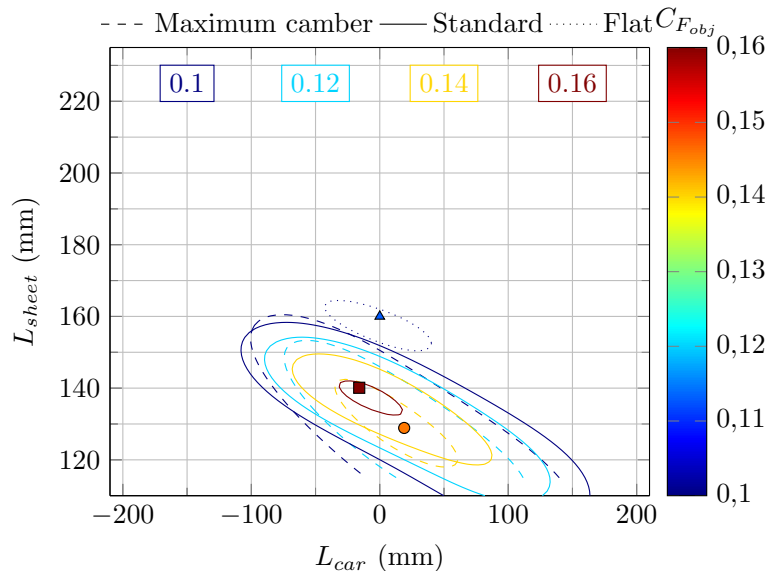

and MSflat for $\beta_{A W}=25^{\circ}$

Figure 7. $C F_{o b j}(\mathrm{x})$ evolution for lower apparent wind angle. The disk mark is associated to the maximum camber mainsail experimental optimum, the square mark is associated to the standard mainsail experimental optimum, the triangle mark is associated to the flat mainsail experimental optimum. 


\section{Dynamic trimming}

The dynamic trimming consists of an oscillation in the sheet length $L_{\text {sheet }}$ around the optimum trimming length obtained previously. The dynamic trimming was done with a fixed traveller position $L_{c a r}$ (obtained from the optimum trimming) and the instantaneous sheet length $L_{\text {sheet }}(t)$ could be calculated from the controlled and recorded angular position of the rotating plate (see figure (8b) and $(8 \mathrm{a})$ ). $L_{\text {sheet }}(t)$, the instantaneous length of the sheet, is a function of $A$ the amplitude of variation in $\mathrm{mm}, f$ the frequency of oscillation (rotation frequency of the stepper motor controlling the rotating plate) in $\mathrm{Hz}$ and the model-scale configuration geometry. The frequency $f$ and amplitude $A$ of oscillation were controlled by the rotating plate placed at the center-line of the boat as illustrated in Figure (8b). The sheet was connected to a pin fixed on the plate. The amplitude of oscillation depends on radial position of the pin. $A=10 \mathrm{~mm}$ stands for an eccentric of $10 \mathrm{~mm}$ and corresponds to a peak to peak amplitude of motion of $20 \mathrm{~mm}$ on $L_{\text {sheet }}$ (oscillation of $L_{\text {sheet }}$ of $\pm 10 \mathrm{~mm}$ ). The scale being $1: 13$, the highest magnitude of oscillation $A=30 \mathrm{~mm}$ is equivalent to a peak to peak sheet length fluctuation of $0.78 \mathrm{~m}$ at full-scale.

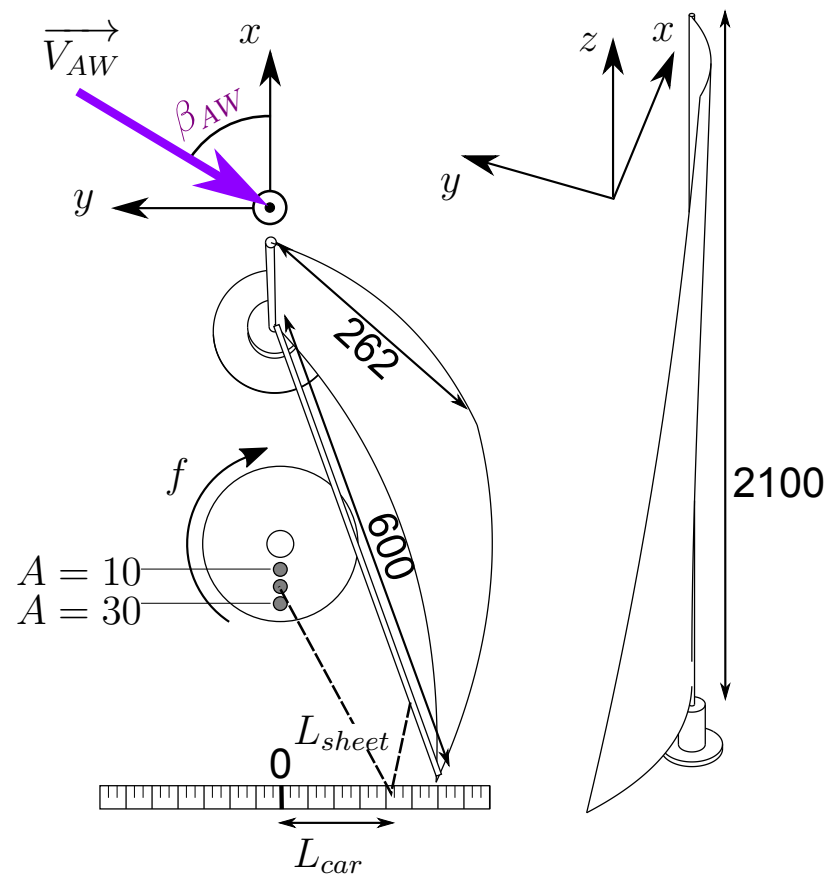

(a) Experimental set up for dynamic trimming Dimensions are in $\mathbf{m m}$.

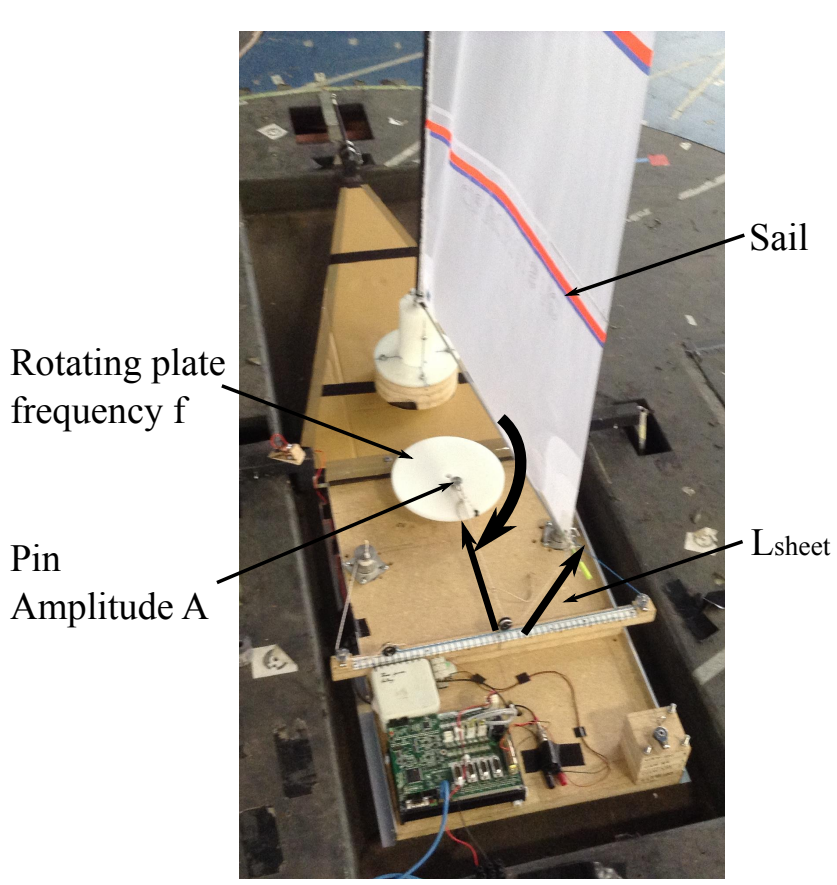

(b) Experimental set up for dynamic trimming: rotating disk (photograph taken without wind)

Figure 8. Description of the dynamic command law.

In these conditions, the dynamic sheet length is given by Eq. 5 as a function of the angular position of the pin (point $P$ in Figure (10)), ie of the angular position of the rotating disk. The initial angular position $\kappa_{0}$ depends of the geometric configuration and is associated to the position of the car traveller fixed at the optimum. $\kappa_{0}=-31^{\circ}$ for the optimum car traveller position here.

$$
\begin{aligned}
L_{\text {sheet }}=\sqrt{\left(A \sin \kappa_{0}-332.5\right)^{2}+\left(A \cos \kappa_{0}-L_{\text {car }}\right)^{2}+1}+L_{\text {sheet }}\left(\kappa_{0}\right) & \\
- & \sqrt{\left(A \sin \kappa_{T}-332.5\right)^{2}+\left(A \cos \kappa_{T}-L_{c a r}\right)^{2}+1}
\end{aligned}
$$


The angular position $\kappa_{T}$ reads as a function of time, the initial angular position $\kappa_{0}$ associated to the optimum trim and the frequency $f$ as $\kappa_{T}=\kappa(t)-\kappa_{0}=2 \pi f t-\kappa_{0}$. A representation for the different amplitude tested is provided in figure (9) on two periods with $f=1 \mathrm{~Hz}$. For some configurations at different apparent wind angle where the optimum is more centered, the difference on $\Delta L_{\text {sheet }}$ between the sinusoid and the equation provided can be up to $5 \%$ of the amplitude $A$.

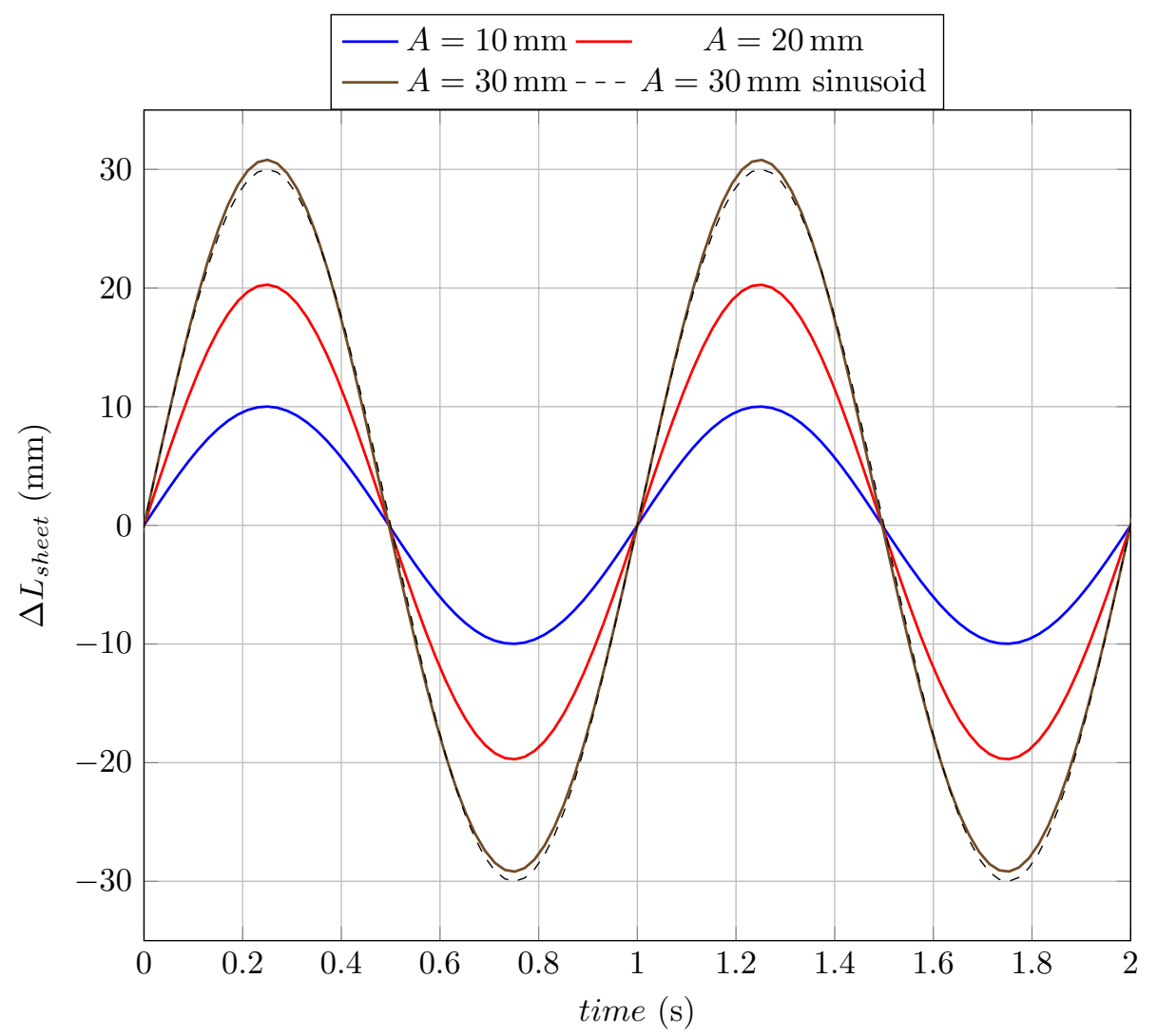

Figure 9. $L_{\text {sheet }}$ fluctuation for $f=1 \mathrm{~Hz}$. A sinusoid model represented for $A=30 \mathrm{~mm}$ differs slightly from the computation of the sheet length fluctuation. 


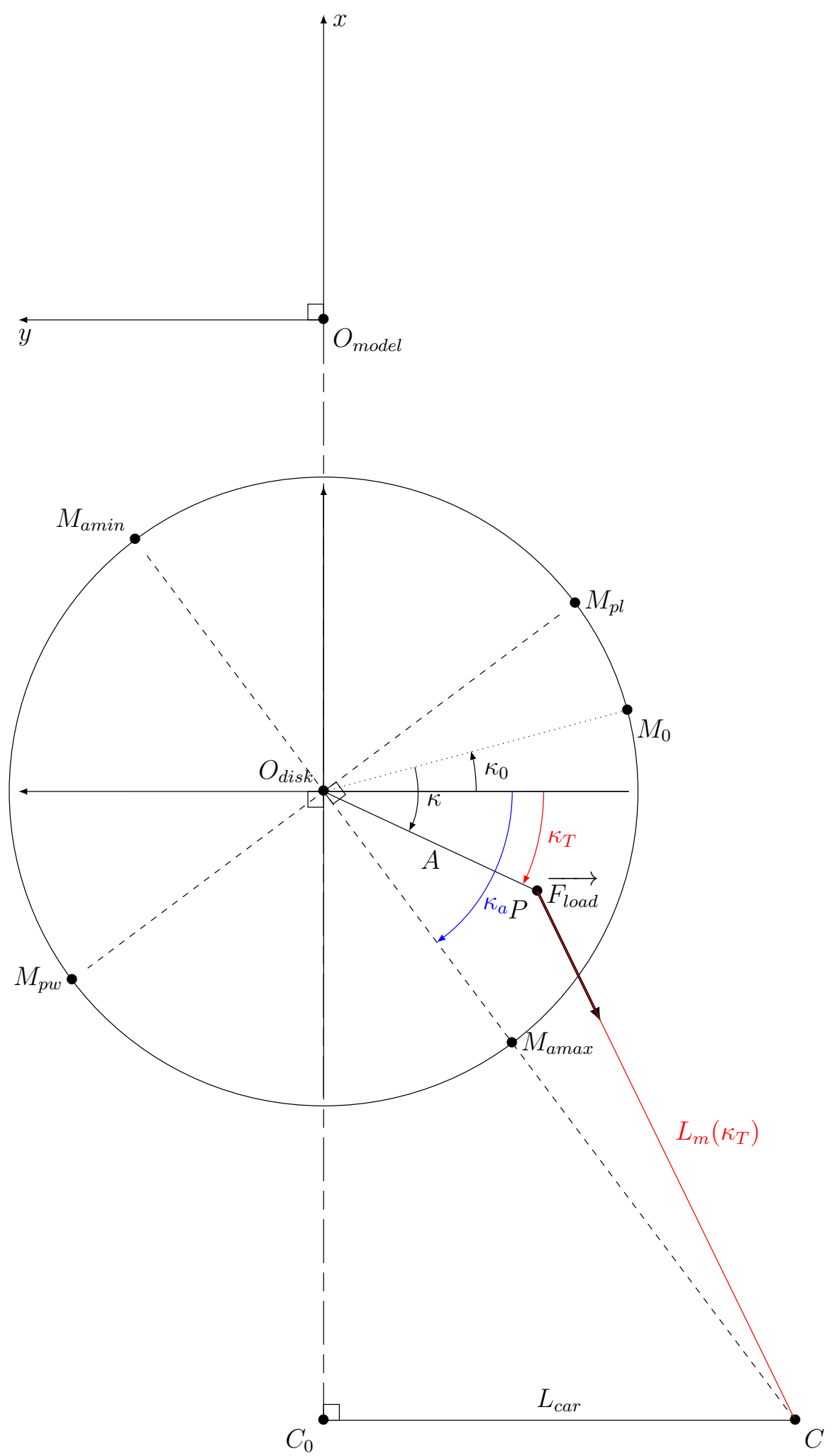

Figure 10. Experimental geometry notation for dynamic trimming seen from above with $O_{\text {disk }} C_{0}=332.5 \mathrm{~mm} . L_{m}$ represents the distance between the pin and the car traveller. $\kappa$ angle indicates the angular positioning of the pin. $\kappa_{0}$ is the angular positioning of the pin associated to the static case tested when $f=0 \mathrm{~Hz}$ (ie $f_{r}=0$ as presented next). 


\section{RESULTS}

We examine here the influence of the dynamic trimming on the aerodynamic forces of the sail. Three different sails were tested for three amplitudes of oscillation of $10 \mathrm{~mm}, 20 \mathrm{~mm}$ and $30 \mathrm{~mm}$ and seven ordered frequencies from $0 \mathrm{~Hz}$ to $3 \mathrm{~Hz}$. From these frequencies, nondimensional reduced frequencies $f_{r}$ are defined in the post processing parameters.

\section{Post processing parameters}

In this study we define the reduced frequency $f_{r}=f . c / U_{r e f}$, with $f$ the frequency of oscillation in $\mathrm{Hz}, c$ the reference chord length $c=S / h=0.475 \mathrm{~m}$ and $U_{\text {ref }}=3.5 \mathrm{~m} / \mathrm{s}$ the reference flow speed. The reduced frequency is a non-dimensional indicator defined as the ratio of the reference convection time over the oscillating motion period, from 0 to 0.38 . The equation of $f_{r}$ is inspired by Fossati and Muggiasca (2011) and differs from the common formula found in literature where a $2 \pi$ factor can be included. Some studies about flapping motion may refer to the reduced frequency presented here as a Strouhal number (Egan et al., 2016; Taylor et al., 2003). The reduced frequency was chosen here to associate the pumping to a forced dynamic action like in Fossati and Muggiasca (2011) and Fossati and Muggiasca (2012) where dynamic pitching effects are investigated on sails which differs from a natural unsteady fluid phenomenon like in Williamson (1988) where Strouhal number is defined. The non respect of full-scale Reynolds number for wind tunnel testing is a known issue in yacht engineering but previous studies (Hawkins, 1998; Hansen et al., 2005; Hansen, 2006) have indicated the low effect of Reynolds variation in our conditions. Forces were averaged over an integer number of period of oscillation regardless of the reduced frequency in order to compare relevant mean values. Time series were filtered with a low pass filter frequencies defined as a Savitzky-Golay filter of order 1 of span 21 samples (Schafer, 2011).

\section{Effect of the reduced frequency $f_{r}$}

We focus here on the effect of the reduced frequency $f_{r}$ on the forces for the case of the standard mainsail (MSstd) for an oscillation amplitude $A=20 \mathrm{~mm}$ round the optimum $L_{\text {sheet }}$. Coefficients were averaged over the maximum number of integer oscillation periods detected in the $30 \mathrm{~s}$ recording. Results are presented in figure (11). Measurements were doubled and showed good repeatability. Up and down triangles represent the maximum amplitude i.e. the maximum and minimum value of the time series.

For the first oscillation frequency studied, $f_{r}<0.02$, the force coefficients decrease compared to the static situation $f_{r}=0$ values. The oscillation is very slow and could be considered as quasi-steady. This quasi-steady oscillation around the optimum $L_{\text {sheet }}$ degrades the performance because the sail is trimmed at a non-optimum point most of the time. For $f_{r}>0.02$, dynamic trimming increases the mean force coefficient, which reaches a maximum around $f_{r}=0.255$.

The aerodynamic forces seem to benefit from an unsteady propulsion phenomenon due to the flapping of the sail. This unsteady propulsion is maximized for a defined range of frequencies and its effect decreases above $f_{r}=0.255$. Amplitudes of variation of the force coefficients, illustrated by the triangles in figure (11), increase significantly until $f_{r}=0.255$ and collapse dramatically at higher frequencies for $C F_{x}$ and $C F_{\text {sheet }}$. In the case of $C F_{y}$, the amplitude of variation keeps increasing with the frequency of oscillation. The results show the effect of dynamic trimming compared to the steady trimming maximizes $C F_{x}$ at a specific range of reduced frequency around 0.255 . 


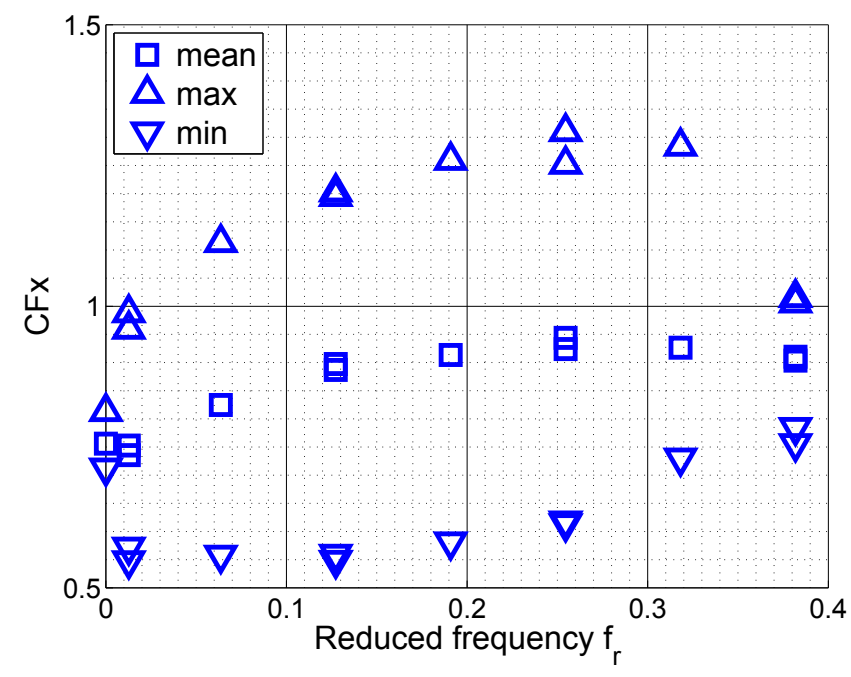

(a) $C F_{x}$ for $A=20 \mathrm{~mm}$

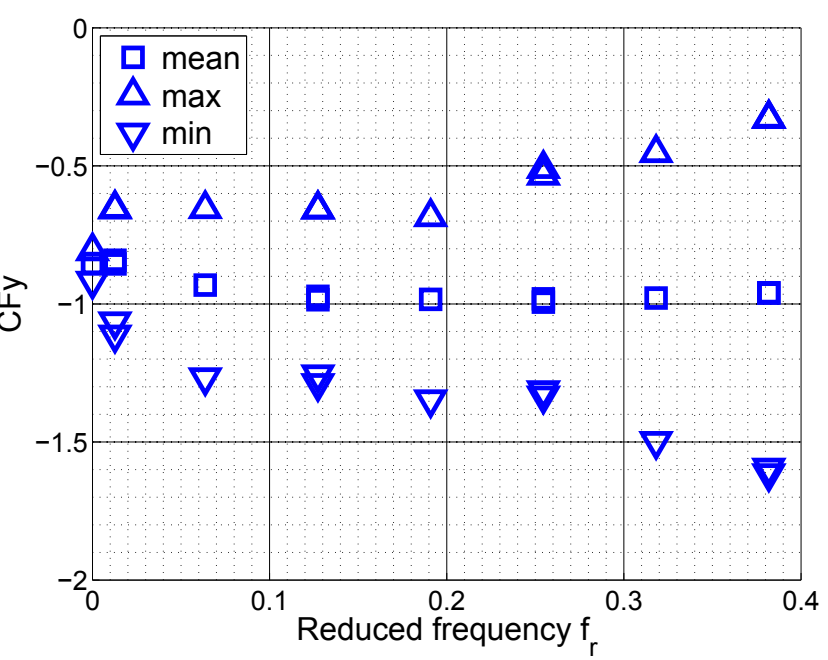

(b) $C F_{y}$ for $A=20 \mathrm{~mm}$

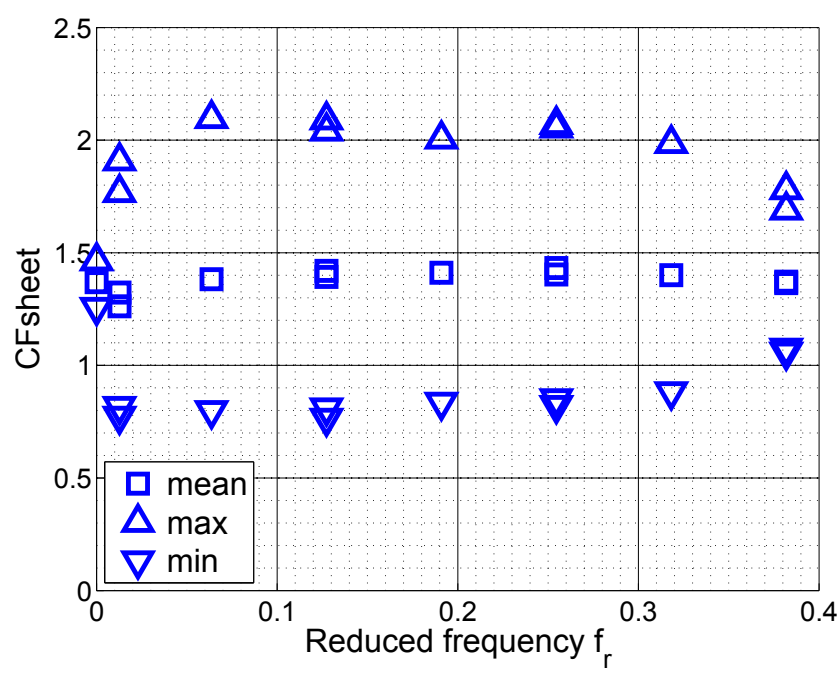

(c) $C F_{\text {sheet }}$ for $A=20 \mathrm{~mm}$

Figure 11. Effect of $f_{r}$ at amplitude $A=20 \mathrm{~mm}$ on $C F_{x}$ (figure (11a)), $C F_{y}$ (figure (11b)) and $C F_{\text {sheet }}$ (figure (11c)) for the standard mainsail. Up and down triangles represent the maximum and minimum amplitude of the time series respectively

Figures (12) and (13) present the temporal evolution of the load in the sheet and the driving coefficient with the sheet length. This type of Lissajou representation was first proposed for a sailing yacht study by Fossati and Muggiasca, 2009; Fossati and Muggiasca, 2010; Fossati and Muggiasca, 2011 in wind tunnel testing and was then used by Augier et al. (2013) and Augier et al. (2014) in simulations and full-scale measurements. For more clarity, signals are represented for only $12 \mathrm{~s}$. We present 4 of the 8 studied frequencies, but the trends are identical. The top graph illustrates the static case. The number of cycles represented increases with the frequency $f_{r}$. All the curves have been centered around the static optimum $L_{\text {sheet static }}$ using $\Delta L_{\text {sheet }}=L_{\text {sheet }}(t)-L_{\text {sheet static }} . \Delta L_{\text {sheet }}=0 \mathrm{~mm}$ is set at the static optimum trim $L_{\text {sheet static }}$ for the optimum of the optimization target $C F_{\text {obj }}$.

$C F_{\text {sheet }}$ vs $\Delta L_{\text {sheet }}$ describes a loop which witnesses a hysteresis phenomenon (figure (12)). In this case, the area inside the loop is proportional to the mechanical work exchanged with 
the rig system from the trimming stepper motor. The counter-clockwise sense of rotation, indicated by the arrow on the figure, shows that the work is negative, i.e. given to the system. This confirms that the sail and rig system are forced by the motion of the sheet for the whole range of studied frequencies. The area in the loop increases slightly until $\mathrm{fr}=0.255$ where it reaches a maximum. The loop collapses at $f r=0.38$. The work exchanged with the rig system is a maximum at $f r=0.255$ which corresponds to the optimum $C F_{x}$ observed in figure (11a).

$C F_{x}$ vs $\Delta L_{\text {sheet }}$ describes a loop as well (figure (13)). One should realise that the area inside the loops is not actual physical work however this representation highlights the difference between a quasi-static approach and an unsteady approach. Moreover considering the dynamic motion of the sail centered on the model mean position when the sail is eased with $\Delta L_{\text {sheet }}>0$, the aeroforces center might go forward along the $x$ direction. On the contrary when the sail is trimmed in $\Delta L_{\text {sheet }}<0$, the aeroforces center might go backwards along the $x$ direction. Therefore considering the aerodynamic center of effort displacement as suggested in Fossati and Muggiasca (2011), the loops indicated here would follow the same orientation as the work energy of $F_{x}$ along the $x$-direction. It is very interesting to observe that the sense of rotation switches for the different frequencies. For $f_{r}=0.013$ and 0.38 , the system dissipates energy as it turns counter-clockwise. The system gains energy from the oscillation at $f_{r}=0.255$ (clockwise rotation). The $f_{r}=0.127$ case is a transition where the loop describes a figure 8 shape.

The dynamic measurement represented in blue in figure (12) deviates from the quasi static measurement in red crosses once the pumping is activated even for a low reduced frequency. The quasi static prediction is only $60 \%$ of the instantaneous dynamic measurement observed at $f_{r}=0.255$ which illustrates the need of dynamic measurement and approach for a correct characterisation. 


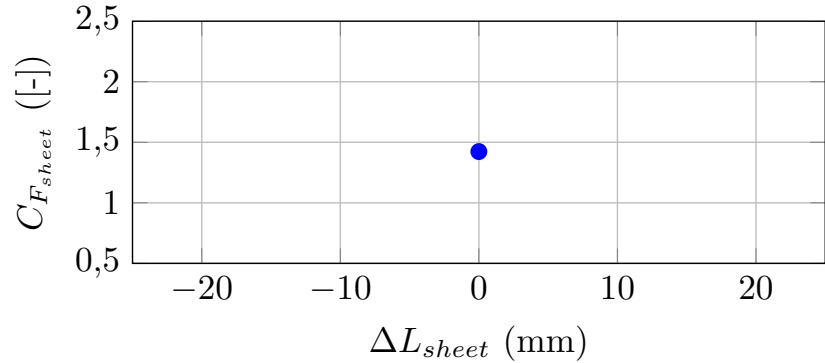

(a) reduced frequency $f_{r}=0$

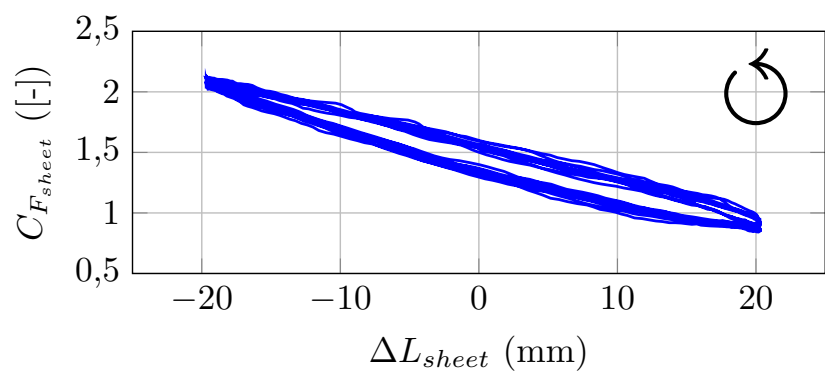

(c) reduced frequency $f_{r}=0.127$

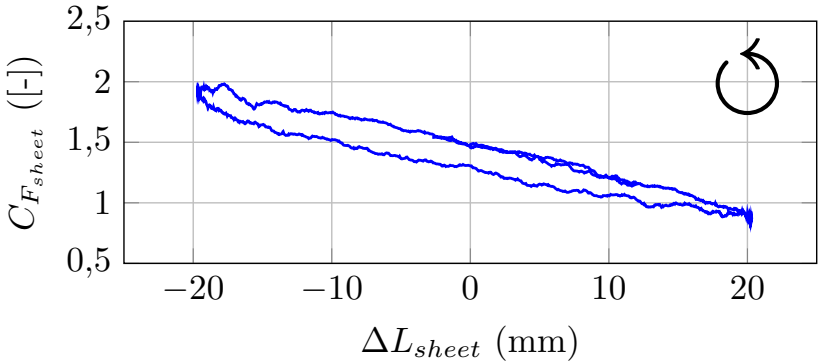

(b) reduced frequency $f_{r}=0.01$

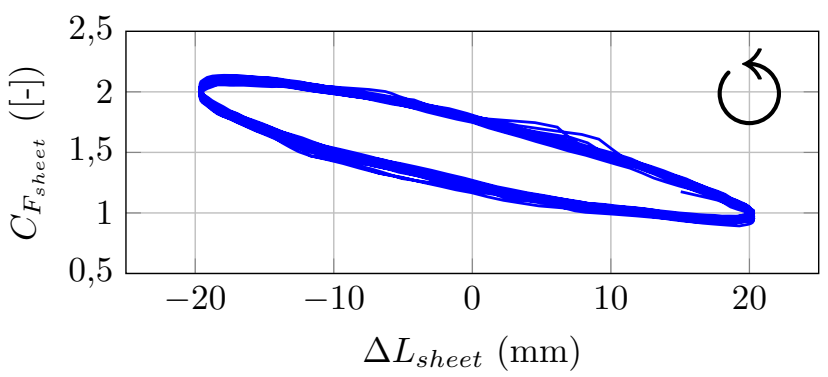

(d) reduced frequency $f_{r}=0.255$

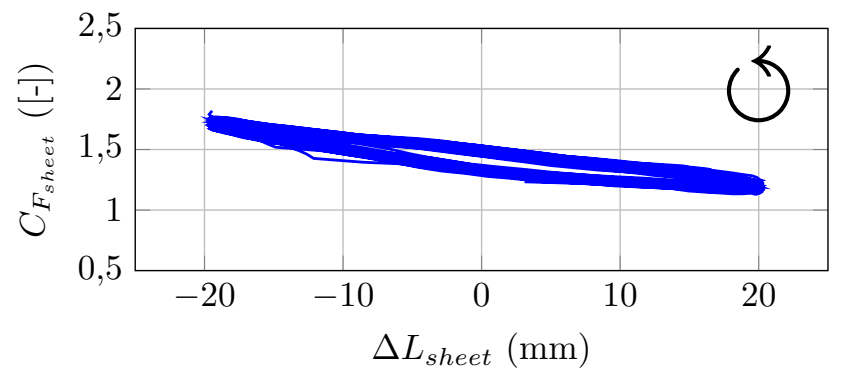

(e) reduced frequency $f_{r}=0.38$

Figure 12. Evolution of $C F_{\text {sheet }}$ with $L_{\text {sheet }}$ at amplitude $A=20 \mathrm{~mm}$ for the standard mainsail for different reduced frequencies. Signals are presented for $12 \mathrm{~s}$. The steady part was done without load sensor, so no steady load sheet is available for this configuration. $\Delta L_{\text {sheet }}=$ $L_{\text {sheet }}(t)-L_{\text {sheet static }}$ 


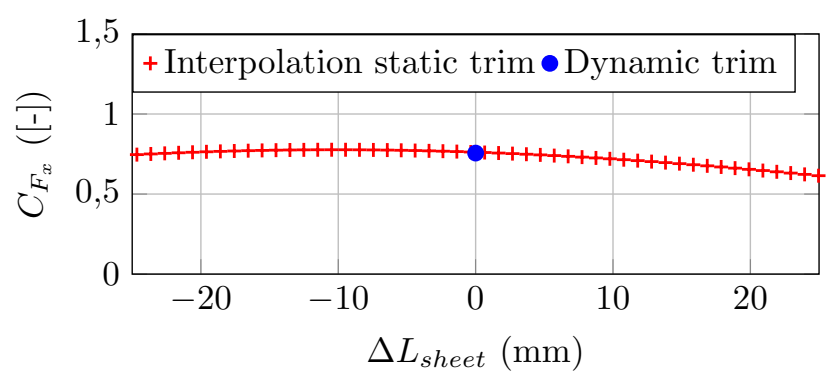

(a) reduced frequency $f_{r}=0$

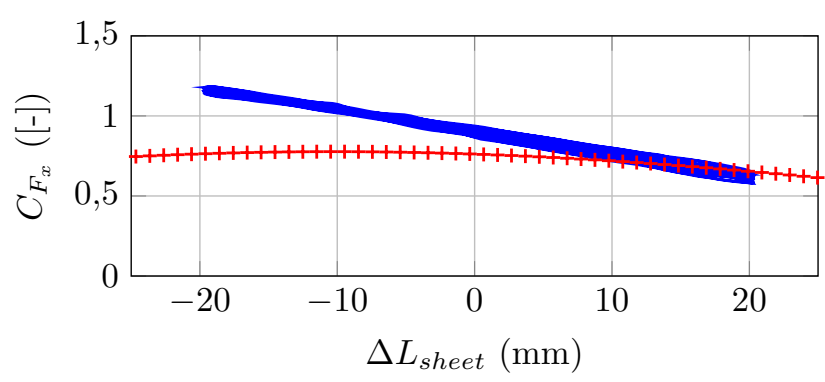

(c) reduced frequency $f_{r}=0.127$

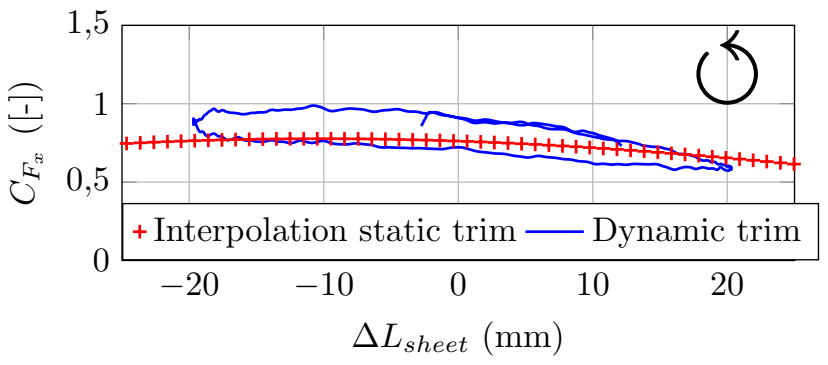

(b) reduced frequency $f_{r}=0.01$

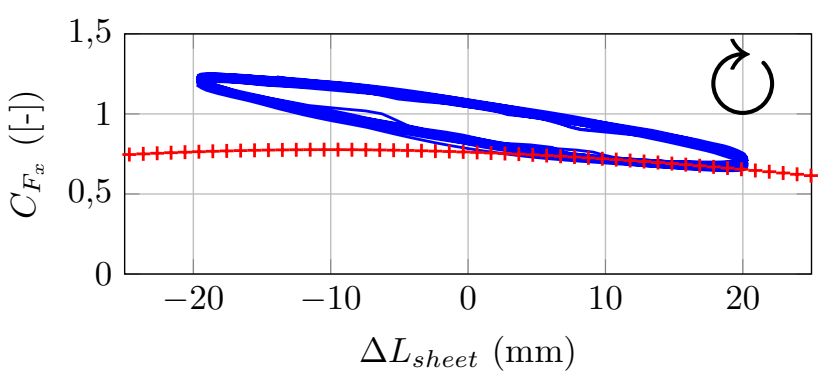

(d) reduced frequency $f_{r}=0.255$

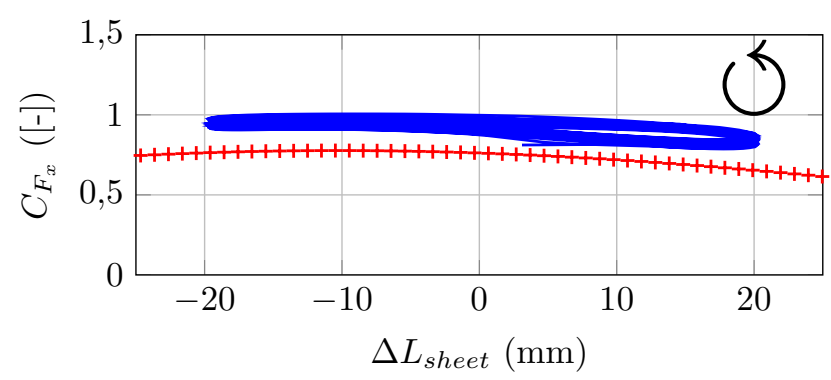

(e) reduced frequency $f_{r}=0.38$

Figure 13. Evolution of $C F_{x}$ with $L_{\text {sheet }}$ at amplitude $A=20 \mathrm{~mm}$ for the standard mainsail for different reduced frequencies. Signals are presented for $12 \mathrm{~s}$. Red crosses represent the steady state interpolated from the 2D optimization part data. $\Delta L_{\text {sheet }}=L_{\text {sheet }}(t)-L_{\text {sheet }}$ static

Power is calculated for each reduced frequency and presented in figure (14). Power is proportional to the area in the loop illustrated in figure (12) and is defined as:

$$
P=\frac{\overline{q(t)} S}{T} \oint_{\text {one loop }} C F_{\text {sheet }}\left(L_{\text {sheet }}\right) d L_{\text {sheet }}
$$

The power value shown on figure (14) is the averaged value of each power value calculated using the previous equation on each entire period oscillation loop. The exchange of energy of the forcing is related to the maximum of force obtained at $f_{r}=0.255$ and the sudden collapse of the amplitude of variation of $C F_{x}$ and $C F_{\text {sheet }}$ at $f_{r}=0.38$. Three different design shape have been tested providing results about the effect of the design shape on the dynamic evolution as presented next. 


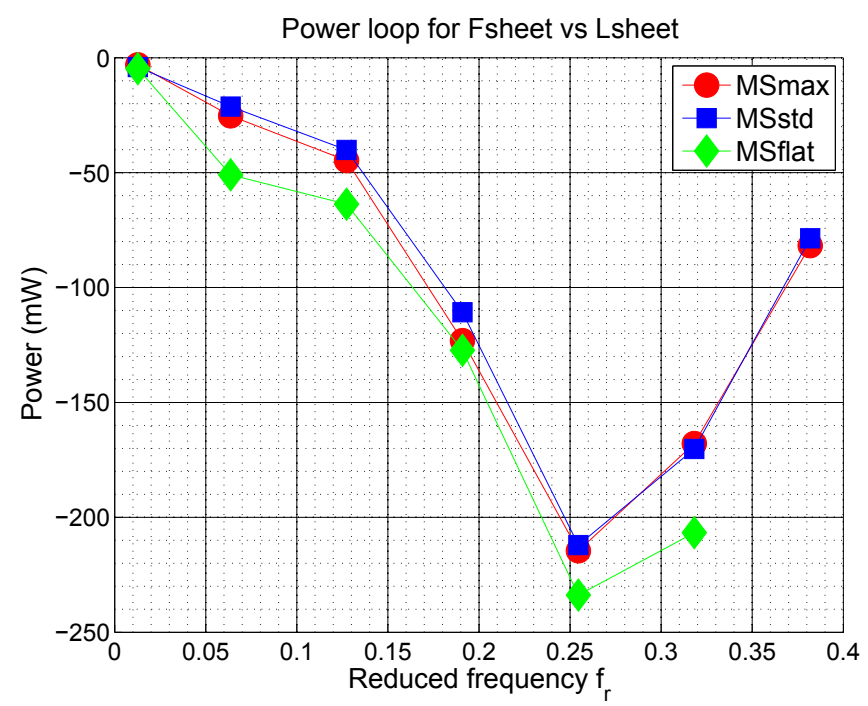

Figure 14. Power given to the sail-air system from the stepper motors through the sheet oscillation forcing at $A=20 \mathrm{~mm}$. Power is proportional to the area in the loop represented in figure (12)

\section{Effect of the design shape}

The effects of the reduced frequency $f_{r}$ on the forces are presented for the 3 design shapes and the 3 amplitudes of oscillation. For each sail, the trimming oscillation is done around its specific optimum. $L_{\text {sheet Static }}$ are different for each case. For these optimum static conditions, the flat mainsail presents a slightly lower sheeting angle (shorter sheet length) than the two other designs. Again, coefficients are averaged over the maximum number of full oscillation periods found in the $30 \mathrm{~s}$ recording. Results are presented in figures (15), (16) and (17), $C F_{x}, C F_{\text {sheet }}$ and $C F_{o b j}$ respectively. Oscillation amplitudes (maximum and minimum value) of force coefficients are not displayed for clarity but trends are identical to those described in the previous section. Due to the parameters of the optimum trimming $\left(L_{\text {sheet }}, L_{\text {car }}\right)$ for the flat mainsail design shape, high frequency oscillations could not be explored at $A=30 \mathrm{~mm}$ because the forcing was too strong. The general trends described in the previous section are identical for the 3 studied sail design shape and the different amplitudes of oscillation. The tendencies observed at $A=20 \mathrm{~mm}$ are amplified at greater amplitude $A=30 \mathrm{~mm}$ and slightly minimized at $A=10 \mathrm{~mm}$. The difference that can be observed in figure (15), figure (16) and figure (17) for the static cases between the different amplitudes for a given mainsail design remains within the uncertainty measurement of force coefficient.

It is interesting to notice that the effect of the dynamic trimming is greater for the flat mainsail design MSflat. The $C F_{x}$ coefficient are nearly identical for the two cambered sails for $A=10 \mathrm{~mm}$ and $A=20 \mathrm{~mm}$ whereas the static performances are significantly worse. It seems that the dynamic behaviour due to flapping compensates for the defect of flat mainsail design MSflat in static conditions. The unsteady propulsion phenomenon is high enough to compensate for the poor aerodynamic performance of the flat sail in a steady trimming. The oscillation needs a minimum of amplitude of $A>10 \mathrm{~mm}$ to have a significant effect on the MSflat. However, the optimum of MSflat is reached for a specific frequency $f_{r}=0.255$ and decreases rapidly around this value, unlike the other sails MSmax and MSstd where the range of optimal frequencies is wider.

The load in the sheet in static situations i.e. $f_{r}=0$ is linked to the camber (figure (16)): the static $C F_{\text {sheet }}$ is greater for the maximum camber mainsail MSmax and it is identical for the 
two other sails. Variations in the load in the sheet $C F_{\text {sheet }}$ for different frequencies are consistent with the effect of dynamic trimming observed on MSflat. The trends are identical with $C F_{x}$. At low oscillation amplitudes, the sheet tension increases significantly for the flat sail until $f_{r}=0.32$, when the $C F_{\text {sheet }}$ reaches a maximum and decreases slightly after $f_{r}=0.13$ for the other sails. For $A=20 \mathrm{~mm}$, the maximum load in the sheet is reached at lower frequencies but a greater load is still necessary to make the flat sail oscillate. It seems that at these amplitudes, the energy brought to the system by the forced oscillation is greater in the case of MSflat, which explains the important gain on the aerodynamic coefficients observed in figures (12) and (13). The differences between the sails are smoothed at $A=30 \mathrm{~mm}$ in $C F_{\text {sheet }}$, as illustrated by the energy brought to the system in $C F_{x}$ and $C F_{y}$. Energy brought to the system by the oscillation of the sheet is illustrated in figure (14). The power exchanged is a maximum at $f_{r}=0.255$.

The $C F_{o b j}$ evolution shown in figure (17) depends on both the camber of the sail and the amplitude of oscillation. For the low oscillation $A=10 \mathrm{~mm}$ in figure (17a), the optimization target shows a maximum for the flat mainsail design contrary to the standard and maximum camber designs which present a plateau from $f_{r}=0.255$. This plateau disappears for higher amplitude oscillations and all the curves present a maximum. The maximum camber design gives the best performance at this angle either in static or dynamic conditions for the highest amplitude tested. For this $\beta_{A W}=60^{\circ}$ this trend confirms the sailors' knowledge causing them to try to increase the camber by easing the outhaul of the sail to improve their performance in a situation such as a dogleg while sailing perpendicular to the true wind direction. 


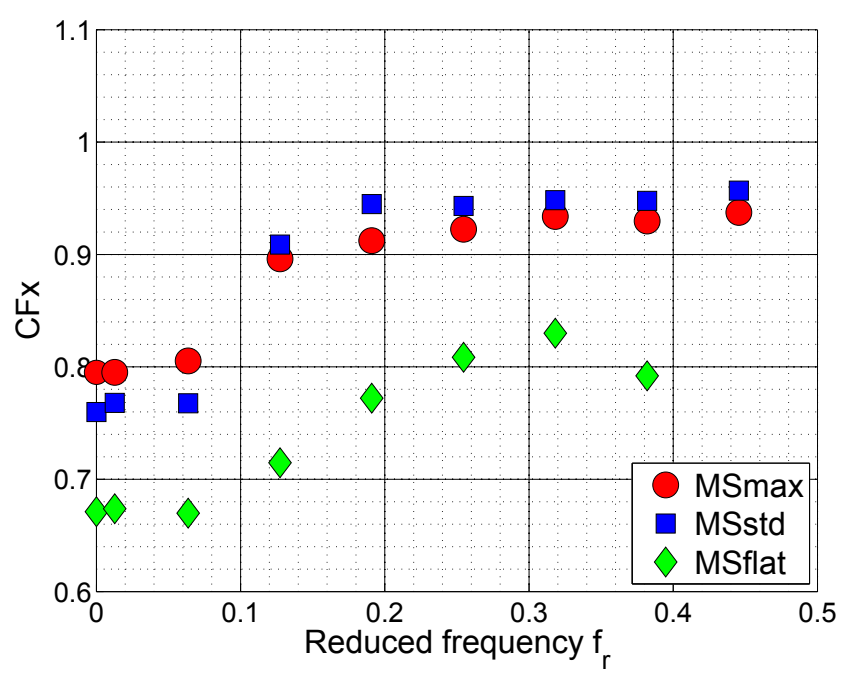

(a) $A=10 \mathrm{~mm}$

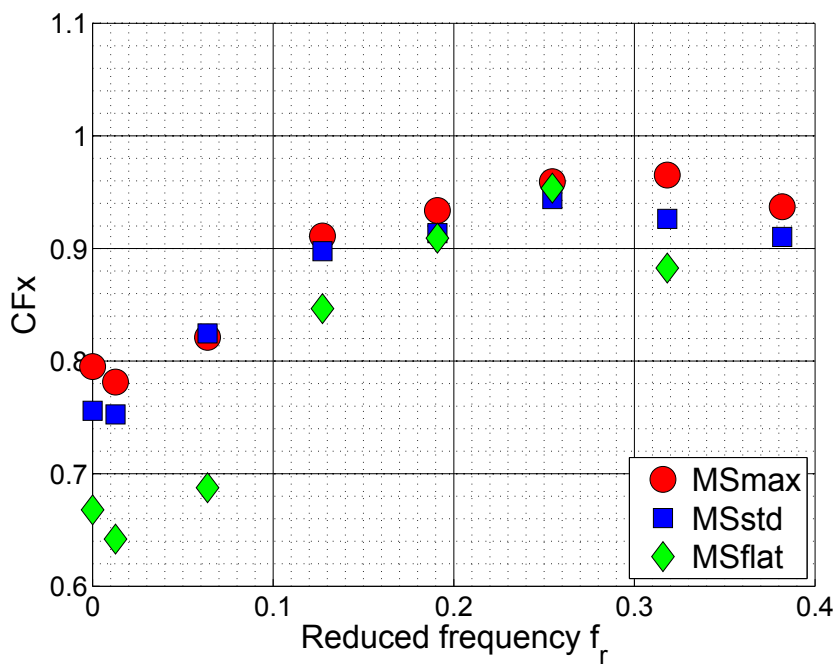

(b) $A=20 \mathrm{~mm}$

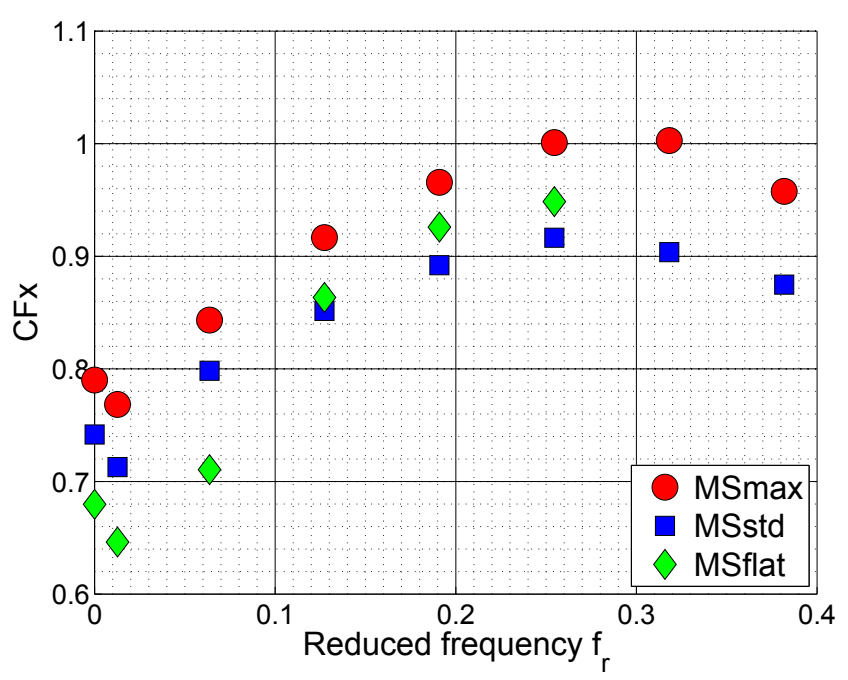

(c) $A=30 \mathrm{~mm}$

Figure 15. Effect of $f_{r}$ on $C F_{x}$ for the 3 design shape at amplitude (a) $A=10 \mathrm{~mm}$, (b) $A=20 \mathrm{~mm}$ and (c) $A=30 \mathrm{~mm}$. 


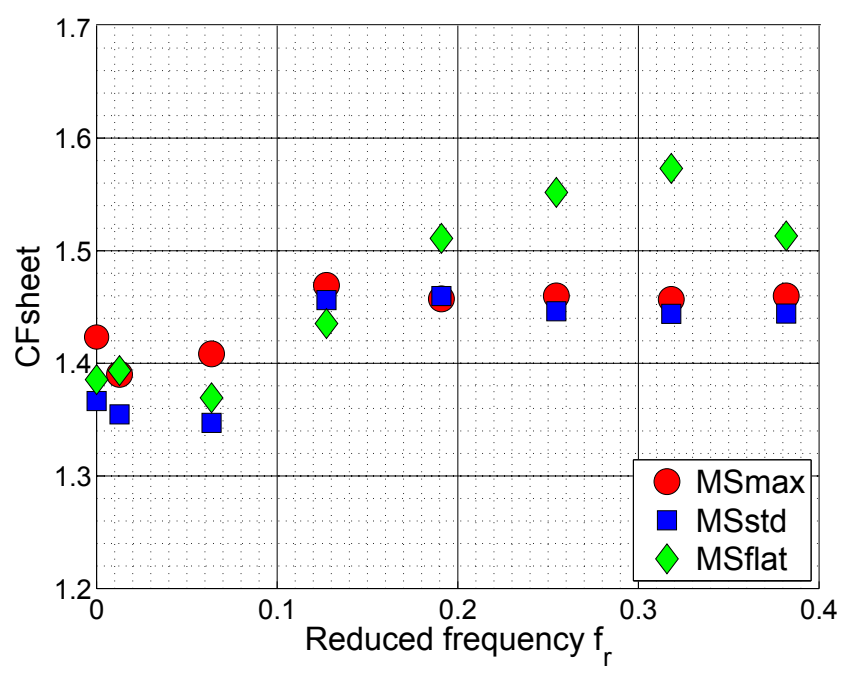

(a) $A=10 \mathrm{~mm}$

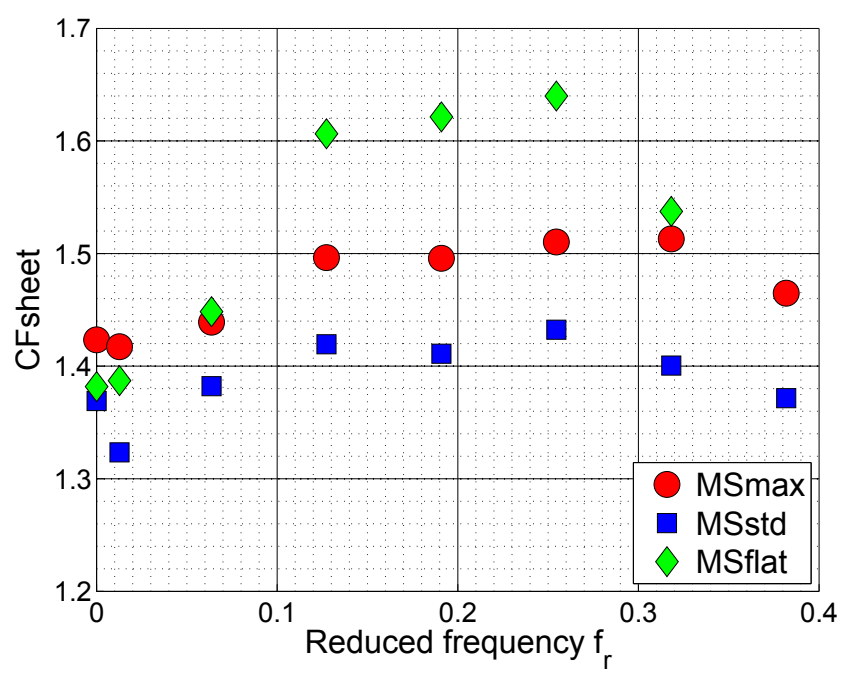

(b) $A=20 \mathrm{~mm}$

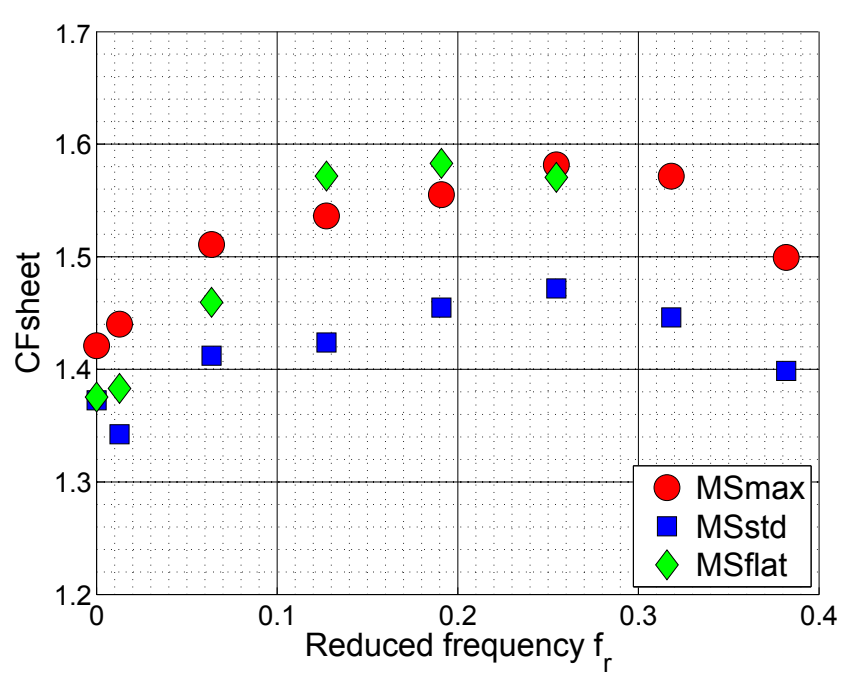

(c) $A=30 \mathrm{~mm}$

Figure 16. Effect of $f_{r}$ on $C F_{\text {sheet }}$ for the 3 design shape at amplitude (a) $A=10 \mathrm{~mm}$, (b) $A=$ $20 \mathrm{~mm}$ and (c) $A=30 \mathrm{~mm}$. 


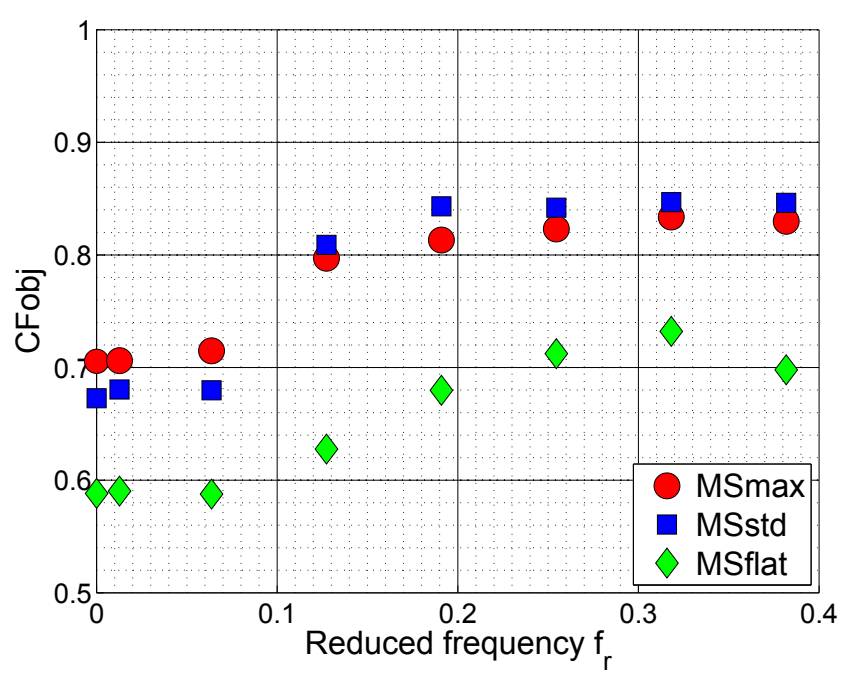

(a) $A=10 \mathrm{~mm}$

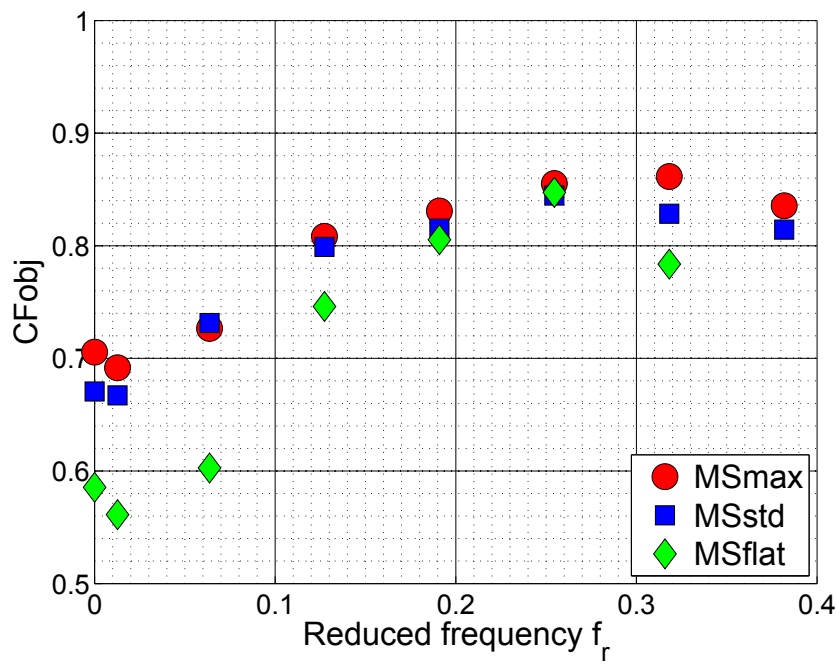

(b) $A=20 \mathrm{~mm}$

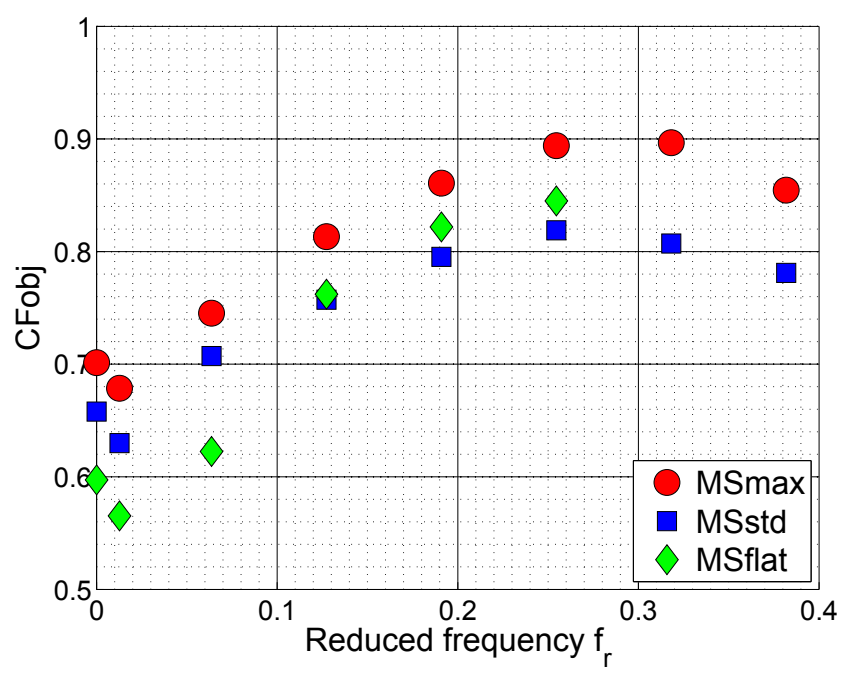

(c) $A=30 \mathrm{~mm}$

Figure 17. Effect of $f_{r}$ on $C F_{o b j}$ for the 3 design shapes at amplitude (a) $A=10 \mathrm{~mm}$, (b) $A=$ $20 \mathrm{~mm}$ and (c) $A=30 \mathrm{~mm}$. 


\section{DISCUSSION}

Dynamic contributions to aerodynamic forces can be decomposed into three components. The first one is due to the change in circulation around the profile. At this AWA $\beta_{A W}=60^{\circ}$, the more camber, the more drive force in static conditions. The second component is due to the unsteady propulsion caused by the forced oscillation. At a certain range of frequencies studied, flapping might produce vortex structures beneficial to the aerodynamic force produced by the sail. Vortex structures are linked to the sail area, the frequency and the amplitude of oscillation but do not depend on the sail profile. This flapping effect on the flat sail MSflat which suffers from a poor static aerodynamic contribution is then much more significant but on a narrow range of frequencies. The different sail geometries under dynamic conditions present the same behaviour. Added mass effect occurs but are more likely oriented along the perpendicular direction of the sail, ie more onto the $y$ direction. Measurement of flapping sails have been done without any wind flow velocity for different trimming frequency without noticing effect on the forces mean value. The incoming flow and static aero forces propulsion are required, which combined with the dynamic trimming affect the mean value measured. The third component is the energy transferred to the system by the oscillation forcing. As mentioned in the section describing the effect of the reduced frequency $f_{r}$, mechanical work is given to the system by the forcing in the sheet (figure (14)). This work is dissipated at most of the frequencies but is beneficial to the thrust at $f_{r}=0.255$ (figure (15)). In the case of a dynamic trimming, the aerodynamic force is composed of the three components with different effects depending on the frequencies and amplitudes of oscillation. It seems that the forcing at $f_{r}=0.255$ benefits from all three components, the reason for the local optimum at that frequency.

Table (1) provides the associated trimming period to match the optimum frequency for different full-scale boats with $U_{\text {ref }}=10 \mathrm{kn}$, showing that the trimming period can be achieved by a trimmer. Most of the time the 42.2 article of the racing rules of sailing (International sailing Federation, 2013) does not allow such a repeated pumping except for some dinghy for given weather conditions (Brummer, 2016). However when it is allowed and possible for dinghies where sheet load is not too high compared to keelboats, the period results are close to the dynamic ones used by professional sailors. Without rules consideration, an automatic trimming device such as the one presented in this study but scaled up could be use, but the gain in the aerodynamic propulsion has to be balanced by the consumption of the device -estimated here as the work transmitted through the mainsail sheet- to determine the best efficiency conditions.

Table 1. Oscillating period value for full scale boat with $f_{r}=0.255$

\begin{tabular}{|c|c|c|c|c|}
\hline Yacht & $S\left(\mathrm{~m}^{2}\right)$ & $h(\mathrm{~m})$ & $c\left(\mathrm{~m}^{2}\right)$ & $T(\mathrm{~s}), U_{\text {ref }}=10 \mathrm{kn}$ \\
\hline Windsurf RSX & 9.5 & 5 & 1.9 & 1.45 \\
\hline Laser radial & 5.76 & 4.56 & 1.26 & 0.96 \\
\hline Nacra 17 & 16.25 & 8.70 & 1.86 & 1.42 \\
\hline J80 & 20 & 9.14 & 2.18 & 1.67 \\
\hline Class 40 & 72 & 19 & 3.79 & 2.89 \\
\hline IMOCA 60 & 175 & 28 & 6.25 & 4.76 \\
\hline Super yacht Comanche & 410 & 46 & 8.9 & 6.79 \\
\hline
\end{tabular}

Fatigue load in pumping cycle, effect on the headsail and influence of the dynamic motion on the boat heel would also be some elements to take into account in the design. The dynamic effect on the aeroforces is likely to affect the dynamic behaviour of the boat. For dinghies, the pumping motion is even often associated with a forced heeling motion generated by 
the sailor to add additional hydrodynamic unsteady propulsion effect and increase the sail motion amplitude strengthening the pumping motion. The dynamic effect on $F_{x}$ is likely to generate a non constant boat speed which however cannot be reproduced in the wind tunnel configuration where the model is fixed.

\section{CONCLUSIONS}

An innovative oscillating trimming experiment has been developed in the Twisted Flow Wind Tunnel at the Yacht Research Unit, University of Auckland. The oscillating trimming effect has been studied on different design shapes of IMOCA 60 type mainsails for an AWA equal to $60^{\circ}$ with different input parameters: amplitude and reduced frequency. The dynamic oscillations clearly show that quasi-static measurements are not relevant for predicting aerodynamic forces even at quite low reduced frequencies. These results support previous findings that static or quasi-static approaches are not sufficient to capture the complexities of dynamic effects, even for the simplified oscillating trimming simulation.

The sheet load measurement enabled us to calculate the mechanical power transmitted from the trimming device to the entire rig and sail system and could be correlated with the aerodynamic force evolutions of the different sails.

The dynamic effect showed that there was an optimum reduced frequency $f_{r}=0.255$ that improved the performance function for the different sails related to a maximum power transmitted to the rig and sails by the sheet. The three different model sails presented the same trends, but the dynamic improvement was more significant for the flat sail: up to an increase of $40 \%$ of its $C F_{o b j}$ at $f_{r}=0.255$ and $A=30 \mathrm{~mm}$ compared to the steady case.

\section{Acknowledgements}

This project has received funding from the European Union's Seventh Program for research, technological development and demonstration under grant agreement No PIRSES-GA-2012318924 and from the Royal Society of New Zealand for the UK-France-NZ collaboration project, SAILING FLUIDS (see www.sailingfluids.org). This work was supported by the French Naval Academy, Brest Métropole Océane, Région Bretagne and the Marie Curie European Union's Seventh Framework Programme (FP7/2007-2013) under REA grant agreement n'PCOFUND-GA-2013-609102 (PRESTIGE-Campus France). This work was supported by the "Laboratoire d'Excellence" LabexMER (ANR-10-LABX-19) and co-funded by a grant from the French government under the program "Investissements d'Avenir".

\section{REFERENCES}

Augier, B., P. Bot, F. Hauville, and M. Durand (2013). "Dynamic Behaviour of a Flexible Yacht Sail Plan". In: Ocean Engineering 66, pp. 32-43.

Augier, B., P. Bot, F. Hauville, and M. Durand (2012). "Experimental validation of unsteady models for fluid structure interaction: Application to yacht sails and rigs". In: Journal of Wind Engineering and Industrial Aerodynamics 101, pp. 53-66. ISSN: 01676105. DoI: 10.1016/j . jweia.2011.11.006. URL: http://linkinghub.elsevier.com/retrieve/pii/S0167610511002352. Augier, B., F. Hauville, P. Bot, N. Aubin, and M. Durand (2014). "Numerical study of a flexible sail plan submitted to pitching: Hysteresis phenomenon and effect of rig adjustments". In: Ocean Engineering 90, pp. 119-128. ISSN: 00298018. DOI: 10.1016/j . oceaneng . 2014. 06. 040. URL: http://linkinghub.elsevier. com/retrieve/pii/S0029801814002534.

Brummer, M. (2016). "Free pumping: endurance, acrobatics and horsepower". In: FinnFare November, pp. 29-31. URL: https://issuu.com/finn-class. 
Chapin, V. and P. Heppel (2010). "Performance optimization of interacting sails through fluid structure coupling". In: 2nd International Conference on Innovation in High Performance Sailing Yachts. Lorient, France.

Charvet, T., F. Hauville, and S. Huberson (1996). "Numerical simulation of the flow over sails in real sailing conditions". In: Journal of Wind Engineering and Industrial Aerodynamics 63.13, pp. 111-129.

Collie, S. and M. Gerritsen (2006). "The challenging turbulent flows past downwind yacht sails and practical application of CFD to them". In: 2nd High Performance Yacht Design Conference. Auckland, New-Zealand.

Deparday, J., P. Bot, F. Hauville, D. Motta, D. J. Le Pelley, and R. G. J. Flay (2014). "Dynamic measurements of pressures, sail shape and forces on a full-scale spinnaker". In: 23rd HISWA Symposium on Yacht Design and Yacht Construction. Amsterdam.

Durand, M., A. Leroyer, C. Lothodé, F. Hauville, M. Visonneau, R. Floch, and L. Guillaume (2014). "FSI investigation on stability of downwind sails with an automatic dynamic trimming". In: Ocean Engineering 90, pp. 129-139. ISSN: 00298018. DOI: 10.1016/ j . oceaneng . 2014. 09.021. URL: http://linkinghub.elsevier.com/retrieve/pii/S002980181400345X.

Duvigneau, R. and P. Chandrashekar (2012). "Kriging-based optimization applied to flow control". In: International Journal for Numerical Methods in Fluids 69.11, pp. 1701-1714.

Egan, B. C., C. J. Brownell, and M. M. Murray (2016). "Experimental assessment of performance characteristics for pitching flexible propulsors". In: Journal of Fluids and Structures 67, pp. 22-33. ISSN: 08899746. DOI: 10 .1016/ j . jfluidstructs . 2016 .09 .003. URL: http: //linkinghub.elsevier.com/retrieve/pii/S0889974616305163.

Flay, R. G. J. (1996). "A twisted flow wind tunnel for testing yacht sails". In: Journal of Wind Engineering and Industrial Aerodynamics 63.1-3, pp. 171-182. ISSN: 01676105. DOI: 10 . 1016/S0167-6105 (96)00080-3.

Fossati, F. (2010). Aero-Hydrodynamics and the Performance of Sailing Yachts: The Science Behind Sailing Yachts and Their Design. Adlard Coles Nautical.

Fossati, F., I. Bayati, F. Orlandini, S. Muggiasca, A. Vandone, G. Mainetti, R. Sala, C. Bertorello, and E. Begovic (2015). "A novel full scale laboratory for yacht engineering research". In: Ocean Engineering 104, pp. 219-237. ISSN: 00298018. DOI: 10 . 1016/ j . oceaneng . 2015. 05.005. URL: http://linkinghub.elsevier.com/retrieve/pii/S0029801815001730.

Fossati, F. and S. Muggiasca (2009). "Sails Aerodynamic Behavior in dynamic condition". In: The 19th Chesapeake Sailing Yacht Symposium. Annapolis, USA.

- (2010). "Numerical modelling of sail aerodynamic behavior in dynamic conditions". In: 2nd International Conference on Innovation in High Performance Sailing Yachts. Lorient, France. - (2011). "Experimental investigation of sail aerodynamic behavior in dynamic conditions". In: Journal of Sailboat Technology 2, pp. 1-41.

- (2012). "An experimental investigation of unsteady sail aerodynamics including sail flexibility". In: 4th High Performance Yacht Design Conference. Auckland, New Zeeland.

Garrett, R. (1996). The symmetry of sailing: the physics of sailing for yachtsmen. Sheridan House, Inc.

Gerhardt, F., R. G. J. Flay, and P. J. Richards (2011). "Unsteady aerodynamics of two interacting yacht sails in two-dimensional potential flow". In: Journal of Fluid Mechanics 668.1, pp. 551-581.

Gerhardt, F. C. (2010). “Unsteady Aerodynamics of Upwind-Sailing and Tacking”. PhD thesis. The University of Auckland.

Graf, K. and O. Müller (2009). "Photogrammetric Investigation of the Flying Shape of Spinnakers in a Twisted Flow Wind Tunnel". In: 19th Chesapeake Sailing Yacht Symposium. March. Annapolis. 
Hansen, H. (2006). "Enhanced wind tunnel techniques and aerodynamic force models for yacht sails". PhD thesis. The University of Auckland, p. 299. URL: https://researchspace. auckland.ac.nz/handle/2292/1759.

Hansen, H., P. J. Richards, and K. Hochkirc (2005). "Advances in the Wind Tunnel Analysis of Yacht Sails". In: 26th Symposium on Yacht Design and Construction, Hamburg, Germany, 4-5 November.

Hawkins, P. (1998). "Non-dimensional number effects on downwind sail modelling". ME thesis. The University of Auckland. URL: https : //researchspace . auckland . ac . nz/handle/ $2292 / 3153$.

International sailing Federation (2013). Racing rules of sailing. URL: http: //www . sailing . org/documents/racingrules/index.php.

Jones, D. R., M. Schonlau, and W. J. Welch (1998). "Efficient Global Optimization of Expensive Black-Box Functions”. In: Journal of Global optimization 13.4, pp. 455-492.

Keuning, J., K. Vermeulen, and E. de Ridder (2005). "A generic mathematical model for the manoeuvring and tacking of a sailing yacht". In: The 17th Chesapeake Sailing Yacht Symposium. Annapolis, USA, pp. 143-163.

Lasher, W. and P. Richards (2007). "Validation of Reynolds-averaged Navier-Stokes simulations for international America's Cup class spinnaker force coefficients in an atmospheric boundary layer." In: Journal of Ship Reseasrch 51 (1), pp. 22-38.

Le Pelley, D. and O. Modral (2008). "VSPARS: A combined sail and rig recognition system using imaging techniques". In: 3rd High Performance Yacht Design Conference 14, pp. 5766.

Le Pelley, D. J., P. Ekblom, and R. G. J. Flay (2002). "Wind tunnel testing of downwind sails". In: 1st High Performance Yacht Design Conference. Auckland, pp. 66-75.

Marchaj, C. (1996). Sail performance: techniques to maximize sail power. International Marine/Ragged Mountain Press.

Masuyama, Y. and T. Fukasawa (1997). "Full scale measurement of sail force and the validation of numerical calculation method". In: The 13th Chesapeake Sailing Yacht Symposium. Annapolis, USA.

Masuyama, Y., Y. Tahara, T. Fukasawa, and N. Maeda (1993). "Dynamic performance of sailing cruiser by a full scale sea reality". In: The 11th Chesapeake Sailing Yacht Symposium. Annapolis, USA.

Ranzenbach, R., D. Armitage, and A. Carrau (2013). "Mainsail Planform Optimization for IRC 52 Using Fluid Structure Interaction". In: 21st Chesapeake Sailing Yacht Symposium. March. Annapolis, pp. 50-58.

Renzsch, H. and K. Graf (2013). "An experimental validation case for fluid-structure-interaction simulations of downwind sails". In: 21st Chesapeake Sailing Yacht Symposium. March. Annapolis, pp. 59-66.

Renzsh, H. and K. Graf (2010). "Fluid Structure Interaction simulation of spinnakers - Getting closer to reality". In: 2nd International Conference on Innovation in High Performance Sailing Yachts. Lorient, France.

Richardt, T., S. Harries, and K. Hochkirch (2005). "Maneuvering simulations for ships and sailing yachts using FRIENDSHIP-Equilibrium as an open modular workbench". In: International Euro-Conference on Computer Applications and Information Technology in the Maritime Industries.

Sacher, M., F. Hauville, P. Bot, and M. Durand (2015). "Sail trimming FSI simulation - comparison of viscous and inviscid flow models to optimise upwind sails trim". In: 5th High Performance Yacht Design Conference. Auckland, New-Zealand, pp. 217-228. 
Sacher, M., F. Hauville, R. Duvigneau, O. L. Maître, N. Aubin, and M. Durand (2017). "Efficient optimization procedure in non-linear fluid-structure interaction problem: Application to mainsail trimming in upwind conditions". In: Journal of Fluids and Structures 69, pp. 209231. ISSN: 0889-9746. DOI: http://dx . doi.org/10.1016/j.jfluidstructs . 2016.12.006. URL: http://www.sciencedirect.com/science/article/pii/S0889974616303437.

Schafer, R. W. (2011). "What Is a Savitzky-Golay Filter?" In: IEEE Signal Processing Magazine 28.4, pp. 111-117.

Schoop, H. and N. Bessert (2001). "Instationary aeroelastic computation of yacht sails". In: International Journal for Numerical Methods in Engineering 52.8, pp. 787-803.

Taylor, G. K., R. L. Nudds, and A. L. R. Thomas (2003). "Flying and swimming animals cruise at a Strouhal number tuned for high power efficiency." In: Nature 425, pp. 707-711. ISSN: 0028-0836. DOI: 10.1038/nature02000.

Trimarchi, D., M. Vidrascu, D. Taunton, S. Turnock, and D. Chapelle (2013). "Wrinkle development analysis in thin sail-like structures using MITC shell finite elements". In: Finite Elements in Analysis and Design 64, pp. 48-64. ISSN: 0168874X. Dol: 10.1016/j f finel .2012.09.005. URL: http://linkinghub.elsevier.com/retrieve/pii/S0168874X12001795.

Viola, I. M. and R. G. J. Flay (2010). "On-water pressure measurements on a modern asymmetric spinnaker". In: 21st HISWA Symposium on Yacht Design and Yacht Construction. November. Amsterdam.

- (2011). "Sail pressures from full-scale, wind-tunnel and numerical investigations". In: Ocean Engineering 38.16, pp. 1733-1743. ISSN: 00298018. DOI: $10.1016 / \mathrm{j}$. oceaneng . 2011.08. 001. URL: http://linkinghub.elsevier.com/retrieve/pii/S0029801811001764.

Viola, I., P. Bot, and M. Riotte (2013). "Upwind sail aerodynamics: A RANS numerical investigation validated with wind tunnel pressure measurements". In: International Journal of Heat and Fluid Flow 39, pp. 90-101. ISSN: 0142727X. DoI: 10. 1016/j . i jheatfluidflow . 2012. 10.004. URL: http://linkinghub.elsevier.com/retrieve/pii/S0142727X12001257.

Williamson, C. H. K. (1988). "Defining a universal and continuous Strouhal-Reynolds number relationship for the laminar vortex shedding of a circular cylinder". In: Physics of Fluids 31.10, pp. 2742-2744. ISSN: 10897666. DOI: 10.1063/1.866978.

Wright, A. M., A. R. Claughton, J. Paton, and R. Lewis (2010). "Off-wind sail performance prediction and optimisation". In: The Second International Conference on Innovation in High Performance Sailing Yachts, Lorient, France.

\section{CITATION}

Aubin, N, et al. (2017). "Wind tunnel investigation of dynamic trimming on upwind sail aerodynamics." Journal of Sailing Technology, 2017-Article No, journal.sailing-technology.com. 